\title{
Monetary Policy Uncertainty
}

Husted, Lucas, John Rogers, and Bo Sun

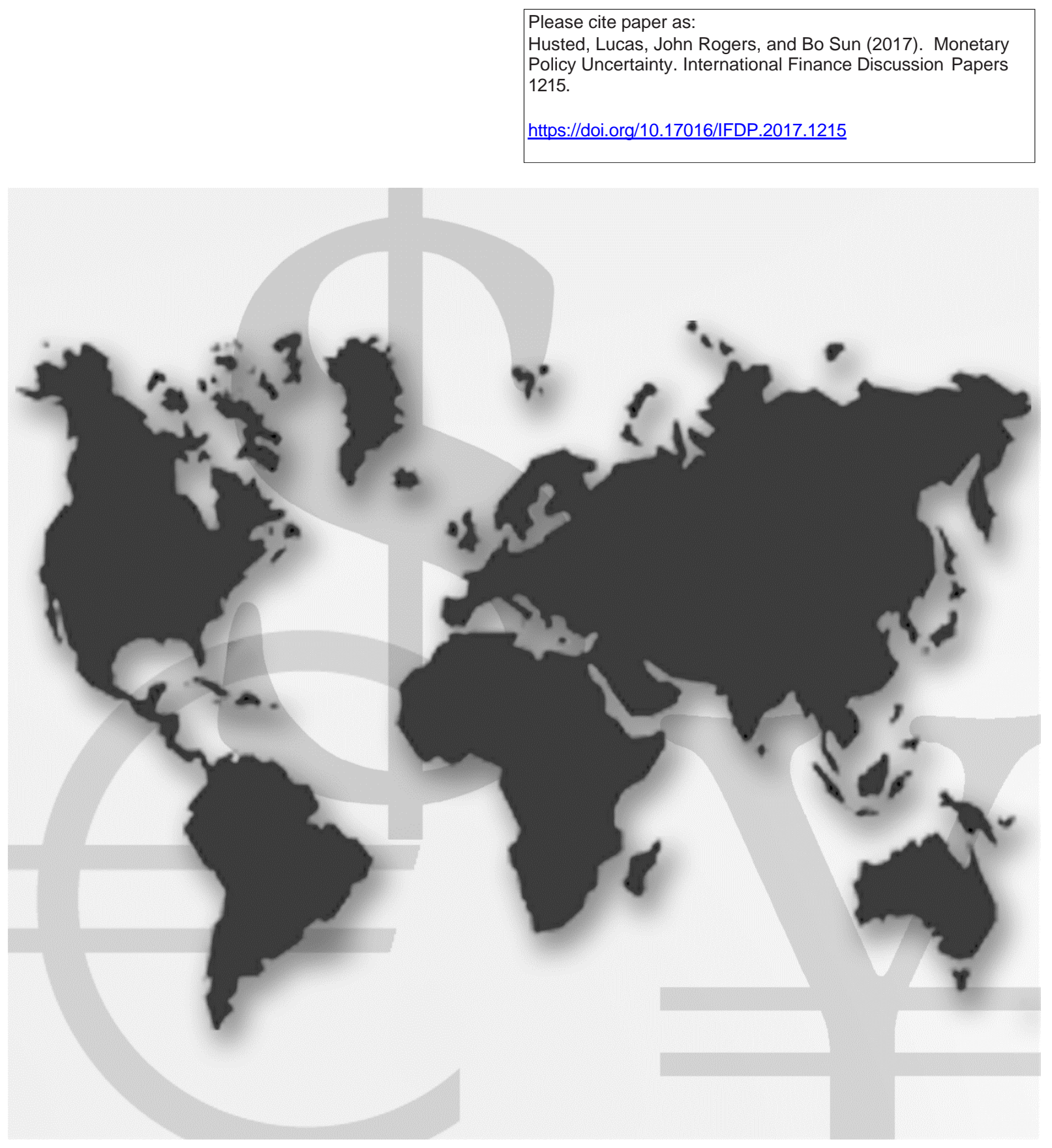

\section{International Finance Discussion Papers}

Board of Governors of the Federal Reserve System

Number 1215

October 2017 


\section{Board of Governors of the Federal Reserve System \\ International Finance Discussion Papers}

Number 1215

October 2017

\section{Monetary Policy Uncertainty}

Lucas Husted, John Rogers, and Bo Sun

NOTE: International Finance Discussion Papers are preliminary materials circulated to stimulate discussion and critical comment. References in publications to International Finance Discussion Papers (other than an acknowledgment that the writer has had access to unpublished material) should be cleared with the author or authors. Recent IFDPs are available on the Web at https://www.federalreserve.gov/econres/ifdp/. This paper can be downloaded without charge from Social Science Research Network electronic library at http://www.sssrn.com. 


\title{
Monetary Policy Uncertainty*
}

\author{
Lucas Husted \\ John Rogers \\ Bo Sun \\ Columbia University \\ Federal Reserve Board \\ Federal Reserve Board
}

${ }^{*}$ We thank workshop participants at the Bank of England, Central Bank of Ireland, Federal Reserve Board, Georgetown University, Hong Kong Monetary Authority, International Monetary Fund, Notre Dame, UNCChapel Hill, Oxford-FRBNY conference on Monetary Economics, and FRB-Chicago System Committee Meeting on Macroeconomics. We thank Scott Baker, Nick Bloom, and Steve Davis for hosting our index on their Economic Policy Uncertainty website. The views expressed here are solely our own and should not be interpreted as reflecting the views of the Board of Governors of the Federal Reserve System or of any other person associated with the Federal Reserve System. 


\title{
Monetary Policy Uncertainty
}

\begin{abstract}
We construct new measures of uncertainty about Federal Reserve policy actions and their consequences - monetary policy uncertainty (MPU) indexes. We show that, under a variety of VAR identification schemes, positive shocks to uncertainty about monetary policy robustly raise credit spreads and reduce output. The effects are of comparable magnitude to those of conventional monetary policy shocks. We evaluate the usefulness of our MPU indexes, and examine the influence of Fed communication. Our analysis suggests that policy rate normalization that is accompanied by reduced uncertainty can help neutralize the contractionary effects of the rate increases themselves.
\end{abstract}

Keywords: Monetary policy uncertainty, VAR identification, FOMC communication JEL Classifications: E40, E50. 


\section{Introduction}

As the Federal Reserve poised itself in 2015 to lift off from the zero interest rate policy in place since 2008, the intentions of monetary policymakers and the effects of their actions once again faced increased scrutiny. Reflecting this monetary policy mise-en-scene, the Financial Times proclaimed on the day after the October 2015 Federal Open Market Committee (FOMC) meeting, "Fed Speaks Plainer English on Rates: A clearer marker has been laid down for a December increase, though divisions remain." In December 2015, the Federal Reserve lifted the policy rate off its effective lower bound in a 25 basis point hike that has been repeated four times since. Although the December 2015 Fed liftoff removed the prevailing uncertainty about when the Fed would finally raise rates, it is less clear more generally what effect liftoff had on uncertainty about monetary policy, including its transmission (Brainard (2017)). Estimating the transmission of shocks to monetary policy uncertainty is the focus of this paper.

Recently, there has been a surge of interest in economic policy uncertainty. ${ }^{1}$ Baker, Bloom, and Davis (2016) develop an index of overall economic policy uncertainty (EPU), including fiscal, monetary, trade, healthcare, national security, and regulatory policies, based on the occurrence of certain keywords in newspaper coverage. The existing literature on monetary policy uncertainty per se predominantly utilizes market-based proxies such as implied volatility computed from interest rate option prices and realized volatility computed from intraday prices of interest rate futures (Neely (2005), Swanson (2006), Bauer (2012), and Chang and Feunou (2013)). ${ }^{2}$ As made evident below, our measure is complementary to these derivative-based measures but differs in three important dimensions, because the market-based measures: (1) reflect the perception of only the households participating in the options market, (2) may have a component driven by time-varying risk aversion and/or state-dependent marginal utility rather than uncertainty and (3) are essentially all about (policy) interest rate uncertainty. Our analysis suggests that there exists a significant degree of uncertainty about monetary policy beyond interest rate fluctuations. ${ }^{3}$

\footnotetext{
${ }^{1}$ See references at http://www.policyuncertainty.com/research.htm, as well as Fischer (2017).

${ }^{2}$ Carlson, Craig and Melick (2005) and Emmons, Lakdawala and Neely (2006) go beyond implied volatility and extract the option-implied probability distribution of future policy rates using federal funds futures options.

${ }^{3} \mathrm{~A}$ related set of papers develops various aspects of uncertainty concerning government policy: Justiniano and Primiceri (2008), Bloom (2009), Rubio-Ramirez, and Uribe (2011), Stock and Watson (2012), Bachmann, Elstner, and Sims (2013), Born, Peter, and Pfeifer (2013), Fernandez-Villaverde, Guerron-Quintana, Kuester, and RubioRamirez (2013), Fernandez-Villaverde, Guerron-Quintana, Nakamura, Sergeyev, and Steinsson (2014), Orlik and Veldkamp (2014), Creal and Wu (2016), Shoag and Veuger (2015), Jurado, Ludvigson, and Ng (2015), and Engen, Laubach, and Reifschneider (2015).
} 
Our paper is also related to a rapidly growing literature using textual analysis to measure economic variables. The news-based search has been recently adopted to construct new measures for a broad economic policy index (Baker, Bloom, and Davis (2016)), partisan conflict (Azzimonti (2017)), geopolitical risk (Caldara and Iacoviello (2017)), and corporate news. ${ }^{4}$ A number of papers use variables generated from publicly released FOMC documents to study FOMC communication, including Boukus and Rosenberg (2006), Ehrmann and Fratzscher (2007), Meade and Stasavage (2008), Schonhardt-Bailey (2013), Acosta and Meade (2014), and Acosta (2015). We update some of these measures. Our paper suggests that text searches can deliver useful proxies of uncertainty tracing back decades.

Specifically, we do three things in this paper. First, we construct a news-based index of monetary policy uncertainty to capture the degree of uncertainty that the public perceives about central bank policy actions and their consequences. We follow the approach in Baker, Bloom, and Davis (2016), and highlight some important advantages of ours. We also detail our "human audit" that assesses the accuracy of our construction approach. We focus on the Fed starting in 1985..$^{5}$ As documented below, large spikes occurred around the September 11 attacks, the March 2003 invasion of Iraq, prior to the October 2015 FOMC meeting when "liftoff uncertainty" seemed to have peaked, Brexit, and the November 2016 elections.

Second, we evaluate the role of MPU in the monetary policy transmission mechanism, estimating the effect of shocks to monetary policy uncertainty in VARs utilizing several different approaches to identification. We examine cases in which the identified MPU shock is by construction orthogonal to monetary policy shocks. We find that positive shocks to MPU raise credit spreads and lower output with about the same dynamic pattern as contractionary monetary policy shocks found in, e.g., Gertler and Karadi (2015).

Last, we provide further discussion that facilitates a better understanding of what our MPU index captures. We examine co-movements of our index with several alternative proxies. Ours fluctuates substantially during the period when policy rates were at the effective lower bound, unlike most competing measures. We investigate whether our MPU index is influenced by institutional measures of central bank policy actions such as voting behavior and newly-constructed

\footnotetext{
${ }^{4}$ For example, Davis, Piger, and Sedor (2006), Tetlock (2007), Engelberg (2008), Tetlock, Saar-Tsechansky and Macskassy (2008), Demers and Vega (2010), Hoberg and Phillips (2010), Feldman, Govindaraj, Livnat and Segal (2010), and Loughran and McDonald (2011).

${ }^{5}$ In Husted, Rogers, and Sun (2016b), we construct these indexes for the ECB and central banks of Canada, England, and Japan.
} 
measures of FOMC communication. We wrap up by linking the discussion to the related theoretical literature.

\section{Measuring Monetary Policy Uncertainty}

\subsection{Construction}

Our approach to constructing the MPU index is to track the frequency of newspaper articles related to monetary policy uncertainty. Using the ProQuest Newsstand and historical archives, we construct the index by searching for keywords related to monetary policy uncertainty in major newspapers. We search for articles containing the triple of (i) "uncertainty" or "uncertain," (ii) "monetary policy(ies)" or "interest rate(s)" or "Federal fund(s) rate" or "Fed fund(s) rate," and (iii) "Federal Reserve" or "the Fed" or "Federal Open Market Committee" or "FOMC". We do this for every day's issue of the Washington Post, Wall Street Journal, and New York Times.

Importantly, we control for the changing volume of total news articles over time and the possibility that some newspapers naturally cover monetary policy more than others by first dividing the raw count of identified articles by the total number of news articles mentioning "Federal Reserve", or more precisely, any of the words in category (iii), for each newspaper in a given period. This scaling choice also helps address issues related to time-varying popularity and increased coverage of the Fed due to improved transparency in its communication strategy. The share of articles is subsequently normalized to have a unit standard deviation for each newspaper over the sample period. Each of our monetary policy uncertainty indexes is aggregated by summing the resulting series and scaling them to have a mean of 100 over the sample. We construct the index at both a monthly frequency and a meeting-interval frequency.

We display our baseline MPU index in Figure 1. The sample is January 1985 to May 2017. The index spikes notably toward the end, especially around the Brexit vote, as well as at the time of Black Monday, the September 11 attacks, the March 2003 invasion of Iraq, the lead-up to the global financial crisis, the Taper Tantrum, and prior to the October 2015 FOMC meeting (when "liftoff uncertainty" seemed to have peaked). Our index thus fluctuates substantially during the period the Federal Funds rate was at the zero lower bound. ${ }^{6}$

\footnotetext{
${ }^{6}$ Consistent with the large spike in March 2003, Bernanke (2015) recalls, "U.S. forces had invaded Iraq a few days before the (March 2003) meeting. Businesses and households were reluctant to invest or borrow until they saw how the invasion would play out. My colleagues and I were also uncertain about the economic consequences of the war, especially its effect on energy prices. At Greenspan's urging, we decided to wait before considering further
} 
We examine the sensitivity of our baseline index by considering several adjustments to its construction. In one refinement, we narrow our search to articles in which the word uncertainty/uncertainties is in close proximity to Federal Reserve or monetary policy. Specifically, we restrict "uncertainty" or "uncertainties" to be within either 5, 10, or 20 words of the phrase "Federal Reserve" or "The Fed" or "monetary policy." In order to better understand the tradeoffs associated with using the proximity refinement and as part of a more general auditing of our automated search, we extracted and read a randomly selected sample of the search results (see Appendix A). The proximity search does appropriately filter out articles that mention all the keywords but do not really discuss monetary policy uncertainty per se. ${ }^{7}$ The trade-off, however, is that the proximity search misses articles that discuss issues related to monetary policy uncertainty but have a somewhat large gap between keywords. ${ }^{8}$ We conclude from these readings that the proximity search has smaller type II error but greater type I error relative to the baseline strategy, as it filters out more of both "false" articles and "correct" articles. The correlation between the baseline index and that constructed using the 10-word proximity search is 0.83 (see Husted, Rogers, and Sun (2016a)).

\subsection{Human auditing}

To address concerns about automated news-based computer search, we conduct an audit based on human readings. We begin by reading and coding randomly-selected 6000 articles and construct a human index based on the share of articles discussing high or rising monetary policy uncertainty. To concentrate on articles that are likely relevant, the random samples we draw are from the set of articles that meet our criterion (iii), that is, containing "Federal Reserve" or "the Fed" or "Federal Open Market Committee" or "FOMC". We compare the evolution of the human index with the computer-automated index, including calculating the Type II error rate. We also characterize the nature of monetary policy uncertainty, quantifying the number of articles on

action. In our post-meeting statement, we said uncertainty was so high that we couldn't usefully characterize the near-term course of the economy or monetary policy. That unprecedented assertion probably added to the public's angst about the economy."

${ }^{7}$ For example, in articles that mention monetary policy or interest rate, "uncertainty" shows up in sentences like the following: "Concerns over Europe have also intensified, as political upheaval has bred uncertainty over whether the euro zone will be able to implement controversial austerity measures."

${ }^{8}$ With our 10-word search, for example, an article with the following sentence was not counted: "That the Fed can, if it chooses, intervene without limit in any credit market — not only mortgage-backed securities but also securities backed by automobile loans or student loans — creates more uncertainty and raises questions about why an independent agency of government should have such power." 
uncertainty concerning Fed actions versus uncertainty about the consequences of those actions. We then read an additional 1500 randomly-selected articles contained in our computer-automated MPU index in order to estimate the Type I error rate associated with our baseline MPU index. Our MPU index shows a remarkably high correlation with the index constructed by human intelligence, and its Type I and Type II error rates are reasonably small and do not exhibit large time-series variation.

\subsubsection{A human index}

Each month the newspapers used to construct our MPU index contain 30,000 articles. Of these, 0.17\% meet our computer-automated criteria to be included in the MPU index. We label this set $(M)$. In constructing our human index, we restrict our reading to articles containing one of the category (iii) words: "Federal Reserve" or "the Fed" or "Federal Open Market Committee" or "FOMC". This set, labelled $(E)$, accounts for about $2 \%$ of the universe of newspaper articles. We choose this set $(E)$ to draw articles from because (i) a pilot audit (human reading of 300 articles) suggests that the mention of Fed is at the heart of relevant discussions, significantly more so than the mention of monetary policy, for example; and (ii) the human index can also be normalized in a way consistent with the computer-generated index, i.e., scaled by the number of articles in set $E$, which could help minimize the effect of sampling uncertainty.

We randomly select about $5 \%$ of the newspaper articles in set $E$ and read the full text of each of these 6000 articles. $^{9}$ Following a detailed auditing guideline, we use text analytic techniques to identify phrases that likely indicate true positives as well as those that are likely associated with false positives. We repeat this process and refine the search words until additional adjustments bring only minor improvements in the error rates (detailed below). For example, although in some instances articles use words such as "anxiety" and "fear" to discuss uncertainty related to monetary policy, including these additional words in the search also generates additional false positives, which on balance does not improve our index. ${ }^{10}$

\footnotetext{
${ }^{9}$ For details of our sampling technique, please see our audit guide available at: https://sites.google.com/site/bosun09/monetary-policy-uncertainty-index.

${ }^{10}$ In our pilot human audit, we noticed for instance that articles in the 1980s and early 1990s use "discount rate" to refer to the monetary policy instrument, while such reference diminished completely in recent years. In addition, we see some articles using words such as "anxiety" and "fear" to discuss uncertainty related to monetary policy. With this in mind, we produced an "MPU 2.0" adding the following words in category (i) of our search: concern(s), or concerned or fear(s) or nervous or worry (worries) or speculate(s) or scare(s) or scared. We also added a proximity constraint that word(s) in category (i) must be within 10 words of those in category (ii) or (iii). MPU 2.0 shows a significantly lower correlation with the human index than does our baseline index.
} 
An article is coded as 1 if it contains references to high or rising uncertainty in monetary policy actions and/or their consequences. Articles are coded as -1 if they contain references to low or declines in such uncertainty, and 0 if the article contains no references to relevant uncertainty. About 26 percent of the articles in set $E$ are coded as 1 from our reading. ${ }^{11}$ Figure 2 displays the human index against the computer-generated MPU index. The correlation is high, at 0.84.

\subsubsection{The nature of monetary policy uncertainty}

In the second stage of our audit, we randomly select 1500 articles from those contained in our MPU index. This accounts for over $10 \%$ of set $M$. Among those articles that are coded as 1 , we code an article as "A" if the discussion pertaining to monetary policy uncertainty is on the Fed's actions and as "B" if on the consequences of the Fed's actions. When an article discusses both, it is coded as "A and B". We find that our index mainly captures uncertainty about the Fed's actions: among the true positives, only $10.6 \%$ are about consequences of Fed actions (including the ones on both actions and consequences). The remainder are about uncertainty concerning Fed actions themselves. During the earlier part of the Zero Lower Bound period (ZLB), newspaper articles were mostly discussing uncertainty about economic implications of ZLB, while uncertainty about Fed actions took center stage in the 2013 Taper Tantrum and in the second half of 2015 .

\subsubsection{Type I vs Type II error}

To further evaluate the statistical properties of our MPU index, we analyze the rate of Type I (false positives) and Type II (false negatives) errors. From our sample reading of (1500) articles belonging to the benchmark, computer-generated MPU index, about 85 percent are classified as mentioning high or rising uncertainty related to monetary policy, judged by human intelligence. The month-to-month variation of this fraction of false positives is minimal, alleviating concerns about time-varying biases. One might be particularly concerned about articles on low or declining monetary policy uncertainty getting included in the MPU index. In our sample, only $3.7 \%$ of the articles in set $M$ (those included in the computer-generated MPU index) discuss falling uncertainty. Figure 3 shows the time-series variation in the Type I error rate. The error rate is quite flat, and clearly uncorrelated with our MPU index itself or with other macroeconomic

\footnotetext{
${ }^{11}$ Human reading is done either by one of the authors or a Fed research assistant.
} 
variables.

Given the time-varying writing styles in newspapers, we are mindful that the ratio of false negatives could also vary systematically over time. We thus calculate the Type II error every month as follows. We first identify the articles in our sample of set $E$ that would be included in the computer-automated index ( $\operatorname{set} M$, which is a strict subset of $E$ ), i.e., containing the triple of key words we search for. In the remaining sample (set $E-M)$, we count the number of articles that contain references to high or rising monetary policy uncertainty, which gives us the Type II error rate. Our Type II error rate is on average 0.24 per year, with a standard deviation of 0.05. This indicates that false negatives are also not a major concern for our index. Figure 4 plots the Type II error rate, which is also very flat and uncorrelated with our MPU index and other macroeconomic indicators.

\section{Response of MPU to Monetary Policy Shocks}

To set the stage for studying the transmission of monetary policy uncertainty shocks, we begin by estimating the effects of monetary policy shocks. This provides a benchmark for gauging the importance of MPU shocks. Our strategy is to take a VAR model that is considered conventional in the literature and add MPU to it (see Ramey (2015) for a recent review). Since our sample period includes the ZLB, our disturbances of interest also include shocks to forward guidance. Thus, we choose as benchmark Gertler and Karadi (2015) (hereafter GK) and follow them in undertaking a high frequency identification of the policy shocks. ${ }^{12}$.

Let $\mathbf{Y}_{t}$ be a vector of economic and financial variables, $\mathbf{A}$ and $\mathbf{C}_{j} \forall j \geq 1$ conformable coefficient matrices, and $\epsilon_{t}$ a vector of structural shocks. The general structural form of the VAR we consider is given by

$$
\mathbf{A} \mathbf{Y}_{t}=\sum_{j} \mathbf{C}_{j} \mathbf{Y}_{t-j}+\epsilon_{t}
$$

Multiplying each side by $\mathbf{A}^{-1}$ yields the reduced form VAR

\footnotetext{
${ }^{12}$ In their abstract, GK note of their findings, "Shocks produce responses in output and inflation that are typical in monetary VAR analysis". See also Stock and Watson (2012) and Rogers, Scotti, and Wright (2016) (RSW).
} 


$$
\mathbf{Y}_{t}=\sum_{j} \mathbf{B}_{j} \mathbf{Y}_{t-j}+\mathbf{u}_{t}
$$

where $\mathbf{u}_{t}=\mathbf{S} \epsilon_{t}$ is the reduced form shock, with $\mathbf{B}_{j}=\mathbf{A}^{-1} \mathbf{C}_{j}, \mathbf{S}=\mathbf{A}^{-1}$.

Let $\mathbf{s}$ denote the column in matrix $\mathbf{S}$ corresponding to the impact on each element of the vector of reduced form residuals $\mathbf{u}_{t}$ of the structural shock $\epsilon_{t}$. To compute the impulse responses to a structural shock, we estimate

$$
\mathbf{Y}_{t}=\sum_{j} \mathbf{B}_{j} \mathbf{Y}_{t-j}+\mathbf{s} \epsilon_{t}
$$

As is well-known, the necessary timing restriction that all the elements of $\mathbf{s}$ are zero except the one that corresponds to the policy indicator of interest is in general problematic, especially when financial variables are included in the VAR such as in our application and GK's. The external instrument approach is well-suited to address this problem. Denoting $\mathbf{Z}_{t}$ as a vector of instrumental variables and $\epsilon_{t}^{q}$ a vector structural shocks other than the policy shock, the identification approach requires that:

$$
E\left[\mathbf{Z}_{t} \epsilon^{\prime}\right]=\psi, E\left[\mathbf{Z}_{t} \epsilon^{q^{\prime}}\right]=\mathbf{0}
$$

That is, $\mathbf{Z}_{t}$ must be correlated with $\epsilon_{t}$, the structural shock of interest, but orthogonal to all of the other shocks.

To estimate the elements in $\mathbf{s}$, we follow GK and proceed as follows. First, estimate $\mathbf{u}_{t}$ from the ordinary least squares regression of the reduced form VAR (2). Second, let $u_{t}$ be the reduced form residual from the equation for the policy indicator of interest and let $\mathbf{u}_{t}^{q}$ be the reduced form residual from the equation for variables $q$ other than the policy indicator. Let $s^{q} \in \mathbf{s}$ be the response of $\mathbf{u}_{t}^{q}$ to a unit increase in the policy shock $\epsilon_{t}$. Then obtain an estimate of the ratio $\mathbf{s}^{q} / \mathbf{s}$ from the two stage least squares regression of $\mathbf{u}_{t}^{q}$ on $u_{t}$, using the instrument set $\mathbf{Z}_{t}$.

We follow GK in employing high frequency measures of policy surprises as external instruments, in order to identify the structural monetary policy shocks, now in the presence of monetary policy uncertainty. To isolate the impact of news about monetary policy, the surprises in futures rates are measured within a tight window around the FOMC decision. The key identifying assumption is that news about the rest of the economy within that window on FOMC day is 
orthogonal to the policy surprise. That is, surprises in Fed Funds futures on FOMC dates are orthogonal to within-window movements in other shocks affecting economic and financial variables. One additional benefit of this approach, as illustrated in GK and RSW among others, is that the policy surprise measure can include shocks to forward guidance. ${ }^{13}$ This is accomplished by incorporating in the instrument set surprises in fed funds futures for contracts that expire at a subsequent date in the future. These surprises in principle reflect revisions in beliefs on FOMC dates about the future path of short-term rates. Following GK, we exploit the HFI approach to identify exogenous monetary policy surprises and then use a full VAR to trace out the dynamic responses of real and financial variables.

We analyze monthly data over the period 1985:01 to 2015:12. The end point is chosen to coincide with the precise ending of the ZLB period. The instrument is the surprise in the three month ahead monthly fed funds futures within a 30 minute window of the FOMC announcement, taken from GK. ${ }^{14}$ As argued by RSW, among others, during the ZLB period monetary policy was aimed at rates of longer maturity (through forward guidance and quantitative easing). Thus, to construct our instrument for updating GK's results, we splice the interest rate futures surprises used in RSW onto those of GK. That is, we use the GK instruments for 1991:01-2008:08 and the RSW instruments for the period 2008:09-2015:12. RSW identify U.S. monetary policy shocks during the ZLB period using the change in five-year Treasury futures from 15 minutes before the time of FOMC announcements to 1 hour 45 minutes afterwards on the days of FOMC announcements (the longer window reflecting the Chair's press conference, begun in 2011).

As noted above, our starting point is the baseline model of GK: a VAR that includes the $\log$ industrial production, the log consumer price index, the one-year government bond rate, and a credit spread, specifically, the Gilchrist and Zakrajsek (GZ) excess bond premium. In addition, we add monetary policy uncertainty. We follow GK in taking the one-year government bond rate, rather than the commonly-used Federal Funds rate, as the relevant monetary policy indicator. As GK argue, using a safe interest rate with a longer maturity than the Fed Funds rate allows one to consider shocks to forward guidance in the overall measure of monetary policy shocks: a component of the reduced form VAR residual for the one-year government bond rate

\footnotetext{
${ }^{13}$ Campbell, Evans, Fisher, and Justiniano (2012) and Campbell, Fisher, Justiniano, and Melosi (2016) discuss the complications associated with interpreting such surprises as pure monetary policy shocks. Their focus is on distinguishing between "Delphic" and "Odyssean" forward guidance.

${ }^{14} \mathrm{GK}$ establish this as a valid external instrument for the one-year government bond rate with the conventional F-test statistic well above 10.
} 
is a monetary policy shock that includes exogenous surprises not only to the current Fed Funds rate but also exogenous surprises in the forward guidance about the path of future rates.

The GZ excess bond premium is the component of the remaining spread between an index of rates of return on corporate securities and the rate on a government bond of a similar maturity after the default risk component is removed. GZ and GK show that the excess bond premium has strong forecasting ability for economic activity, outperforming every other financial indicator and thus providing a convenient summary of much of the information from variables left out of the VAR that may be relevant to economic activity.

Figure 5 displays the impulse responses to an identified monetary policy shock in the fivevariable VAR estimated over the period 1985:1-2015:12. ${ }^{15}$ In each case, the panels report the estimated impulse responses along with 68 percent confidence bands, computed using bootstrapping methods.

The impulse responses are almost identical to those reported by GK: a surprise monetary tightening induces a roughly 25 basis point increase in the one-year government bond rate. There is a significant decline in industrial production that reaches a trough roughly two years after the shock. Also consistent with standard theory, there is a very small decline in the consumer price index though it is not statistically significant. The excess bond premium increases by 25 basis points on impact and returns to trend after roughly a year. This increase in the excess bond premium following the monetary policy tightening is consistent with a credit channel effect on borrowing costs.

Finally, we find no significant response of MPU, suggesting that MPU is largely unaffected by conventional monetary policy shocks. This result is interesting in its own right and is also somewhat reassuring: conceptually, our MPU is a "second-moment" variable that should be mostly orthogonal to the first-moment movement in monetary policy. Our no-response result, at a minimum, indicates that our measure of monetary policy uncertainty captures information that is distinct from what is contained in contemporaneous monetary policy shocks.

\section{MPU and Aggregate Economic Activity}

We now turn to the central question: how do economic and financial variables respond to exogenous shocks to monetary policy uncertainty? We do so using several commonly-used identification

\footnotetext{
${ }^{15}$ We replicate GK for their sample period prior to beginning our exercises.
} 
methods: Cholesky decompositions, sign restrictions, and external instruments. Our estimates consistently indicate that monetary policy uncertainty shocks lead to weaker economic performance and tightened credit costs. Furthermore, comparison with the results above indicates that the estimated contractionary effects of positive MPU shocks are as large as those of monetary policy tightening shocks. ${ }^{16}$

\subsection{Cholesky decomposition}

We start with the most commonly used identification method, a standard Cholesky decomposition (Sims (1980)). ${ }^{17}$ We assume the following recursive structure of the VAR:

$$
\mathbf{Y}_{t}=\left[i p_{t}, c p i_{t}, m p u_{t}, i_{t}, e b p_{t}\right]
$$

Under the assumed ordering, monetary policy uncertainty can have an immediate impact on the monetary policy indicator and excess bond premium. Innovations in the interest rate and excess bond premium do not affect MPU contemporaneously, which is consistent with our findings in Section 3. Here, we are interested in identifying shocks to MPU and their transmission effects, and we therefore impose as few restrictions as possible: the current specification allows the policy rate and the excess bond premium to respond simultaneously to MPU, which we consider plausible given how financial markets work. ${ }^{18}$

The left panels of Figure 6 show the impulse responses following a one standard deviation surprise increase in MPU. The sample period is again 1985:01-2015:12. There is a drop in the one-year government bond rate, perhaps induced by the central bank responding to the increased uncertainty by lowering the policy rate. The excess bond premium rises on impact, suggestive of increased borrowing costs in response to positive shocks to monetary policy uncertainty. Finally, despite the loosening of interest rates, industrial output and inflation fall on impact and reach a trough roughly in month 17.

\footnotetext{
${ }^{16}$ In Table 1, we summarize the magnitude of effects from the various VAR identification schemes. Related to our analysis of this section, and with similar conclusions, Creal and $\mathrm{Wu}$ (2016) also examine the transmission of monetary policy uncertainty shocks, using very different uncertainty measures and estimation framework.

${ }^{17} \mathrm{GK}$ also utilize results from Cholesky decompositions as a comparator. Baker, Bloom, and Davis (2016) rely exclusively on this identification scheme.

${ }^{18}$ We find similar results in Cholesky identifications with MPU ordered first.
} 


\subsection{Sign restrictions}

The results from the Cholesky decomposition are useful, serving as an easily-replicated comparison case, but as is well understood it is necessary to examine robustness to alternative identification schemes. Faust (1998) and Uhlig (1997, 2005) developed a method to incorporate "reasonableness" of responses to monetary policy shocks without undercutting scientific inquiry by imposing sign restrictions on the responses of variables other than the ones whose responses are the subject of that inquiry.

We follow suit, estimating the five-variable VAR imposing that the one-year rate and excess bond premium must rise on impact following a one standard deviation surprise increase in MPU. Thus, we assess the transmission of MPU shocks to output and inflation when the policy indicator is not allowed to fall (motivated by the ZLB period).

We display impulse responses for the sign restrictions case in the far right column of Figure 6 and for ease of comparison display the Cholesky and sign restriction cases together in the middle column. The excess bond premium increases on impact by roughly 20 basis points, an amount that is statistically significant. The spread remains elevated above 5 basis points for roughly another year. Compared to the standard Cholesky identification, the declines in industrial production and consumer price index are greater and more persistent under sign restrictions, although not statistically significant in the case of CPI. This follows conventional reasoning, given that the interest rate cannot fall.

We note that the relationship between monetary policy uncertainty and interest rate is ambiguous conceptually. Consider the one-year bond rate to be the expectation of future (overnight) policy rates plus a term premium. During the ZLB period, it is likely that higher MPU raises term premiums without affecting expectations of future policy rates and hence raises the oneyear bond rate. Away from the ZLB, however, higher MPU could lead to lower interest rates as expected future policy rates fall. We take note of this in discussing the remainder of our results. ${ }^{19}$

\subsection{External Instruments}

We turn to estimating the transmission of MPU shocks using the external instruments approach, described in section 3 for the case of identifying monetary policy shocks. Here, we will use as

\footnotetext{
${ }^{19}$ When we estimate using external instrument over 1994-2015, thereby with a larger fraction of the sample being ZLB years, the interest rate response to MPU is indeed more positive (compared to the full-sample case also using external instrument), displayed in Figure F.7 in Appendix F.
} 
our instrument the "monetary policy uncertainty surprise". This is constructed as the change in uncertainty around FOMC meeting days, orthogonalized with respect to the monetary policy surprise described in section 3. Denote the daily implied volatility on the eighth eurodollar futures contract $\sigma(E D 8)_{t}$. This is a measure of uncertainty about future monetary policy. We regress the change in implied volatility from the day before the FOMC meeting to the day of the meeting on the "spliced monetary policy instrument" of GK/RSW on FOMC meeting days, ${ }^{20}$

$$
\Delta \sigma(E D 8)_{t}=\gamma \text { policy } \text { surprises }_{t}+\eta_{t}
$$

The residual from this regression, $\eta_{t}$, is the monetary policy uncertainty surprise. ${ }^{21}$ This instru- $^{-}$ ment series is monthly. It takes on a value equal to the uncertainty surprise in months when there is an FOMC meeting and zero when there is not. The orthogonalization is important because at the ZLB, a downward shift in the expected path of policy will mechanically lower interest rate uncertainty. Our approach thus provides valid instruments by using high-frequency data, with the key identifying assumption that shocks to the economy and monetary policy (within narrow windows around FOMC announcements) are uncorrelated with the residual.

Figure 7 displays the impulse responses estimated using external instruments. Once again, we observe that positive shocks to MPU are contractionary: there is a fairly rapid decline in IP which reaches a trough in about 18 months; the EBP remains elevated for over a year before reverting to trend; the CPI response is insignificant, as in the GK replication analysis, while the interest rate response eventually becomes negative in order to offset the contractionary effects on IP and EBP.

Finally, we estimate the external instruments VAR with the human index replacing the baseline index. We find very similar results, as noted in the next section.

\subsection{Comparison across identification schemes}

The VAR analysis suggests that monetary policy uncertainty shocks lead to weaker macroeconomic performance and tightened credit costs. In Table 1, we compare the size of the impulse

\footnotetext{
${ }^{20}$ Note that this amounts to a timing assumption about MPU and MP shocks, whereby the former are contemporaneously uncorrelated with the latter. This seems reasonable on a priori grounds, and is also buttressed by our IRFs showing the insignificant response of MPU to GK monetary policy shocks.

${ }^{21}$ This is in the spirit of Akkaya, Gurkaynak, Kisacikoglu, and Wright (2015). We have tried several measures of high-frequency monetary policy surprises on the right hand side. These included surprises on instruments at various horizons from 1-quarter ahead to 8. All produced essentially the same results. We choose the spliced GK/RSW instrument for comparability with the results in the previous section (GK replication).
} 
responses to MPU shocks under the various VAR identification schemes we consider. Furthermore, we compare these to the magnitude of the responses to monetary policy shocks in GK and in our replication and updating of their results. We report responses of MPU, interest rate, IP, and CPI on impact, at horizon 12, and at its maximum.

\subsubsection{Monetary Policy Shocks (magnitude)}

The first two columns display results for monetary policy shocks under the external instruments identification for Gertler and Karadi's VAR in two different sample periods: GK's original 1979:07-2012:06 and our sample period for estimating MPU shocks 1985:01-2015:12. In these cases, MPU is not in the VAR. As seen in row 2, interest rates rise on impact by about 20 basis points. The CPI does not change much on impact but eventually falls. IP declines following the contractionary monetary policy shock, with a peak effect occurring around the two-year mark. Notice that the magnitude of the decline in IP is considerably larger in the updated sample compared to GK's initial results. In column 3, we add MPU to the VAR, corresponding to the case reported in Figure 5. The results are nearly identical to those of column 2: adding MPU to the GK VAR has essentially no effect on the transmission of monetary policy shocks.

\subsubsection{MPU Shocks (magnitude)}

The remaining columns of Table 1 report the effects of MPU shocks. In each case, the shock is normalized to a rise in MPU of around 36 points, approximately one standard deviation. Comparing columns 4 and 5, the Cholesky and sign restrictions cases depicted in Figure 6, we see declines in IP and CPI that are equal to or greater than the declines observed in response to monetary policy shocks. For example, in the case of sign restrictions, the rise in MPU leads to a maximum drop in IP of 1.12 percent compared to 1.11 for monetary policy shocks in the fivevariable GK case. Both of these maximum declines occur at around the two year horizon. Notice from the results at month 12 that the responses to monetary policy shocks unfold more rapidly and are shorter-lived than the responses to MPU shocks under Cholesky or sign restrictions.

Turning to the external instruments cases (column 6-8), we see very large contractionary transmission effects of MPU shocks, estimating either with the baseline MPU index, the human index, or with baseline MPU index over the sub-sample 1994-2015. The rise in MPU (normalized) produces a decline in IP that is comparable to the drop observed in response to monetary policy shocks. 


\section{Further Discussions of MPU}

In order to provide a deeper understanding of what our MPU index captures, in this section we compare our MPU index to alternative measures of monetary policy uncertainty, and examine the evolution of our index both during FOMC meeting cycles and over the full sample. In addition, to provide a theoretical underpinning for our VAR results, we illustrate a potential transmission mechanism of monetary policy uncertainty in an extended version of McKay, Nakamura, and Steinsson (2016).

\subsection{Alternative measures of monetary policy uncertainty}

We compare our baseline MPU index to a number of alternative measures that have been used as proxies for monetary policy uncertainty. The first is from the Federal Reserve Bank of New York's Survey of Primary Dealers, which is conducted one week before each FOMC meeting. The Survey is available beginning in 2004, and has the appealing feature of asking respondents to directly report both their forecasted policy rates and their forecast uncertainty. We use the dealers' responses to the following question, over the time period for which this question was relevant and hence asked (i.e., through late 2012): "Of the possible outcomes below (that is, -50 bps, $-25 \mathrm{bps},+0 \mathrm{bps},+25 \mathrm{bps},+50 \mathrm{bps})$, please indicate the percent chance you attach to the indicated policy move at each of the next three FOMC meetings". To gauge the respondents' perceived uncertainty regarding monetary policy, we calculate the average within-respondent standard deviation of forecasted policy rates.

Our baseline MPU index tracks the survey-based uncertainty measure closely prior to 2008 when the effective zero bound was reached, with a correlation of 0.75 for the one-meeting ahead forecast and progressively slightly less for each of the next two meeting-ahead forecasts (Figure 8). This suggests that news-based search results capture the intensity of concerns over both near-term and longer-term horizons, with a relatively stronger focus on the near-term.

In the months preceding the actual liftoff in December 2015, it was apparent that a major component of monetary policy uncertainty centered on the timing of liftoff. We thus also construct from the Primary Dealers Survey a measure of liftoff uncertainty in a manner similar to the interest rate uncertainty above. The Survey began asking respondents to judge the likelihood of liftoff over a pre-defined horizon consisting of 6 - 11 time periods, starting in April 2010. Our MPU index moves quite closely with Primary Dealers' liftoff uncertainty during 2015 (Figure 
9), consistent with the notion that in that year monetary policy uncertainty more generally was primarily about expectations concerning the timing of liftoff.

Second, we compare our MPU index to two market-based indicators of monetary policy uncertainty. In Figure 10 we display our measure against the implied volatility of options on one-year swap rates (swaptions), taken from Carlston and Ochoa (2016). Note that as the shortterm policy rate approached zero, the market-based indicator fell quickly and remained extremely low during the ZLB period. This suggests that the market-based measures do not fully capture monetary policy uncertainty in a broad sense. Episodes such as the Taper Tantrum in 2013 and financial market turmoil prior to the October 2015 FOMC meeting suggest that uncertainty regarding the timing and pace of policy rate normalization was far from zero. Our MPU measure is more strongly correlated with one-year swaption volatility, shown above, than the ten-year (not shown), reinforcing the notion that our measure captures more of the near-term course of policy. In addition, we compare our index to the VIX, the stock market options-based implied volatility measure that has been widely used as a proxy for uncertainty (Bloom, 2009). Our measure of monetary policy uncertainty is positively correlated with the VIX, but only weakly so. ${ }^{22}$

Compared to these measures based on survey data and market volatility, our measure therefore has the advantage of (1) being available in countries and during time periods when market or survey data are not available and (2) better capturing uncertainty in periods with unconventional monetary policy when the policy rate is at or near the lower bound.

We also compare our baseline MPU with the Baker, Bloom, and Davis' (2016) Monetary Policy sub-index of EPU, which is only correlated with our MPU index at 0.46. Our index construction differs from theirs along three dimensions (indexes are displayed in Figure 11). First, they use the Access World News database of over 2,000 newspapers while we focus on three leading newspapers that are tailored to national economic and financial news. Second, our keyword search features a more refined focus on monetary policy in the U.S., while Baker, Bloom, and Davis (2016) include a considerably broader set of words in a string of "or"s that potentially include discussions of other central banks or Fed chairman, for example, "Bernanke", "Volker", "Greenspan", "central bank", "Fed chairman", "Fed chair", "European Central Bank", "ECB", "Bank of England", "Bank of Japan", "BOJ", "Bank of China", "Bundesbank", "Bank of France", "Bank of Italy". Third, they scale the total number of identified articles by the

\footnotetext{
${ }^{22}$ See Husted, Rogers, and Sun (2016a).
} 
total number of articles rather than the number mentioning "Federal Reserve" (broadly). In order to understand the importance of these different index construction strategies, we conduct a "reconciliation analysis" in Appendix D. We conclude from our reconciliation analysis that in order of importance, the factors explaining the weak correlation between MPU-HRS and MPUBBD can be ranked: (1) Newspapers, (2) Keywords, and (3) Scaling. Given their significantly larger set of search terms and newspapers, it is likely that theirs captures a relatively larger global factor while ours is more U.S. centric. ${ }^{23}$

\subsection{Movements in MPU around central bank meeting days}

To further understanding of our MPU index, we examine how it evolves on the days before and after policy meeting days. It is natural to expect that monetary policy uncertainty would decline after the FOMC meets, assuming that policy (in)actions and the associated explanations help mitigate near-term uncertainty about monetary policy. Furthermore, it is logical that enhanced FOMC communication policies will affect uncertainty. These considerations lead us to examine the level of monetary policy uncertainty around FOMC meetings in two sub-periods: February 1994-November 2008 and December 2008-January 2016. ${ }^{24}$

The results are depicted in Figure 12. In both sub-periods, there is a rise in MPU in the days prior to FOMC meetings. In the earlier sub-period, MPU peaks on the day after the FOMC meeting, the first day of newspaper coverage. Comparing the two lines, we see that in the latter sub-period, when the FOMC began to rely increasingly on forward guidance, this rise in MPU is greatly muted and uncertainty peaks one day sooner. ${ }^{25}$ Checking articles' time-stamping indicates that this finding is not a mechanical result of earlier on-line availability of news in the latter sub-period. The evidence is thus consistent with the notion that enhanced communications policies helped ease uncertainty regarding monetary policy by building in expectations of both the near-term and longer-term course of monetary policy.

\footnotetext{
${ }^{23}$ We also repeat the VAR analysis for these alternative measures of monetary policy uncertainty and report similar results in Appendix F.

${ }^{24}$ It is natural to believe that newspaper coverage of monetary policy also rises in the days proceeding FOMC meetings and declines afterward. Hence the importance of our dividing the raw count of identified articles by the number mentioning "Federal Reserve".

${ }^{25}$ Our MPU index rises on the day after the FOMC meetings in the February 1994- November 2008 sample: From human reading of these articles, we note that news articles on the day after the meetings often discuss (1) uncertainties in economic consequences of the Fed decision and/or (2) uncertainties in near-term/future monetary policy actions although current uncertainty seems to have abated.
} 


\subsection{Does FOMC Communication Influence MPU?}

Commentators on central banking have long emphasized factors such as transparency and credibility. Concerning the current communication regime at the Fed, Bernanke (2015) recently opined: "I hope that the Fed's increased transparency will help it maintain its independence, even as it remains democratically accountable. The chair's press conferences, the expanded economic and interest rate projections by FOMC participants, and the lively debate evident in Fed policymakers' speeches continue to provide the Congress, the public, and the markets with considerable information about the Fed's strategy and its rationale. The days of secretive central banking are long gone. The Federal Reserve is not only one of the world's most transparent central banks, it is also one of the most transparent government agencies in Washington."

Indeed, it wasn't always this way. Goodfriend (1986) notes that the Federal Reserve formerly held a strong penchant for secrecy. In an influential theoretical paper, Cukierman and Meltzer (1986) examine the implications of a central bank's informational advantage for policymaker credibility and inflation. They establish conditions under which ambiguity and imperfect credibility are preferable from the point of view of the policymaker to explicit formulation of objectives and perfect credibility. In an extension, Faust and Svensson (1999, 2001) study central bank transparency, credibility, and reputation. They derive the endogenously determined degree of transparency, show that an equilibrium with low transparency is a likely outcome of the model, and assert that it is (was) appropriate to characterize the Federal Reserve and Bundesbank in that way. However, the 1990s elicited fresh analysis from central banking theory, and was accompanied by a sea change of monetary policy making across the globe (Inflation Reports, inflation targeting). Woodford (2013) and Bianchi and Melosi (2017) both find advantages for a central bank that communicates explicitly about its future policy. ${ }^{26}$

In Table 2, we characterize the relationship between our index of monetary policy uncertainty and variables that proxy for the considerations noted above. These variables are discussed in detail in Appendix E. We focus on institutional or procedural features, including dissenting votes, member turnover, and newly-constructed measures of "FOMC statement persistence" and

\footnotetext{
${ }^{26}$ Milton Friedman (1990) is perhaps most blunt about the FOMC and the long gone days referred to by Bernanke: "From revealed preference, I suspect that by far and away the two most important variables in their loss functions are avoiding accountability on the one hand and achieving public prestige on the other". More recently, in "The Fed's Communication Breakdown," Project Syndicate, November 13, 2015, Ken Rogoff echoes Faust-Svensson's theoretical finding, remarking, "however good its intentions, the net effect of too much Fed speak has been vagueness and uncertainty."
} 
"FOMC-revealed uncertainty" (displayed in Appendix E). We also include a dummy variable for the crisis period of $2008 \mathrm{H} 2$, as well as separate dummies for the terms of different FOMC Chairs. To allay concerns about endogeneity, we also control for U.S. macroeconomic uncertainty (Jurado, Ludvigson, and Ng (2015)), financial uncertainty (Ludvigson, Ma, and Ng (2016), and global geopolitical risk (Caldara and Iacoviello (2017)).

We estimate regressions of the form

$$
M P U_{t}=\alpha+\beta \mathcal{X}_{t-1}+\gamma \mathcal{Z}_{t}+u_{t}
$$

where $\mathcal{X}_{t-1}$ includes the prior-meeting values of the institutional variables noted above: dissenting votes, statement persistence, member turnover, and FOMC-revealed uncertainty. Similarly, $\mathcal{Z}_{t}$ represents current-period values of the control variables: macroeconomic uncertainty, financial uncertainty, and geopolitical risk. We also include separate dummies for each Fed chairperson. We pay close attention to the timing, e.g., associating dissenting votes at the current meeting with MPU over the following inter-meeting period. ${ }^{27}$

As seen in Table 2, the regression coefficients are mostly of the anticipated sign. Statement Persistence is negative and significant: greater similarity in the language used by the FOMC in its Statement from meeting to meeting is followed by lower MPU. We also find that greater financial uncertainty and geopolitical risk are robustly followed by higher MPU.

This analysis indicates that there is some significant effect of FOMC communications on MPU. However, at a deeper level the conceptual underpinning of our MPU index is potentially quite encompassing. Consider the increased importance of forward guidance, especially as interest rates hit the effective lower bound. Gurkaynak, Sack, and Swanson (2005) show that much of the surprise news about monetary policy at the time of FOMC announcements arises from signals about the central bank's intentions about future monetary policy. Far future forward guidance has also been shown to be extremely powerful (e.g. Eggertsson and Woodford (2003), Carlstrom, Fuerst, and Paustian (2012), Del Negro, Giannoni, and Patterson (2013)): promises about far future interest rates have huge effects on current economic outcomes, and these effects grow with the horizon of the forward guidance. However, uncertainty also grows with the horizon of central bank promises, given limited central bank credibility and imperfect communication strategies. Episodes of financial turmoil, for example, around the Taper Tantrum of 2013 and prior to the

\footnotetext{
${ }^{27}$ We also tried several other controls, e.g., natural disaster and Ramey fiscal policy shocks, but found them to be insignificant. Appendix E describes all of the variables used in this analysis.
} 
October 2015 FOMC meeting, make apparent that a great deal of uncertainty exists regarding the timing of liftoff, which has a strong economic effect. Our MPU index is able to capture this important element of uncertainty regarding monetary policy, namely, the timing and path of future interest rates. As we saw above, MPU shocks have strong contractionary effects on real and financial variables in the aggregate.

There is also a theoretical literature examining the effects of uncertainty on central bank communication and policy rules. An earlier part of the literature modeled uncertainty about the interest rate rule. Rudebusch $(2001,2002)$ considers uncertainty about the parameters in the central bank's policy rule, as well as real-time data uncertainty. Ehrmann-Smets (2003) examine implications of optimal monetary policy when the central bank follows a Taylor Rule but there is uncertainty about potential output. One result that emerges is that it is optimal to appoint a more "hawkish" central bank. Levin-Wieland-Williams (2003) consider optimal monetary policy when the central bank has model uncertainty, i.e., it does not know the "true" model of the economy and so considers several alternatives. They identify the key characteristics of policy rules that are robust to such uncertainty. In Eusepi-Preston (2010), agents have uncertainty about the interest rate path that the central bank will follow, while the central bank has uncertainty about the economic state. They show that, absent communication, the Taylor principle is not sufficient for macroeconomic stability, and analyze several different communication strategies for the central bank to follow. More recently, Bianchi-Melosi (2016, 2017) model monetary policy under the assumption that agents have uncertainty about whether the central bank is following "passive" or "active" inflation stabilization.

\subsection{Power of Forward Guidance under Uncertainty}

Taking a cue from the literature above, in this section we provide a concrete example of what, conceptually, our MPU captures and its potential effects on the real economy. We extend McKay, Nakamura, and Steinsson (2016) (hereafter, MNS) to allow for uncertainty in forward guidance. These authors use a model with uninsurable idiosyncratic shocks to household productivity, borrowing constraints, and nominal rigidities, to analyze the economic effects of forward guidance. We incorporate into their framework uncertainty about whether the Fed would change the rate as promised.

Standard monetary models imply that far future forward guidance has large effects on current 
outcomes, and that these effects grow with the horizon of the forward guidance. MNS show that in a model with incomplete markets, forward guidance has substantially less power to stimulate the economy, because a precautionary savings effect tempers households' responses to changes in future interest rates. In their model, there is some probability that one will face a borrowing constraint before the promised future interest rate reduction, effectively shortening one's planning horizon. Also, households that are subject to uninsurable idiosyncratic income risk and borrowing constraints will be reluctant to run down their wealth since this will reduce their ability to smooth consumption in the face of future income shocks.

The MNS economy is populated by a unit continuum of ex ante identical households with preferences given by

$$
E_{0} \sum_{t=0}^{\infty} \beta^{t}\left[\frac{C_{h t}^{1-\gamma}}{1-\gamma}-\frac{l_{h t}^{1+\psi}}{1+\psi}\right],
$$

where $C_{h, t}$ is consumption of household $h$ at time $t$ and $l_{h, t}$ is labor supply of household $h$ at time $t$. Households are endowed with stochastic idiosyncratic productivity $z_{h, t}$ that generates pretax labor income $W_{t} z_{h, t} l_{h, t}$, where $W_{t}$ is the aggregate real wage. Each household's productivity $z_{h, t}$ follows a Markov chain with transition probabilities $\operatorname{Pr}\left(z_{h, t+1} \mid z_{h, t}\right)$. The initial cross-sectional distribution of idiosyncratic productivities is equal to the ergodic distribution of this Markov chain, denoted by $\tau\left(Z_{i t}\right)$.

A final good is produced from intermediate inputs according to $Y_{t}=\left(\int_{0}^{1} y_{t}(j)^{1 / \mu} d j\right)^{\mu}$, where $Y_{t}$ denotes the quantity of the final good produced at time $t$ and $y_{j, t}$ denotes the quantity of the intermediate good produced by firm $j$ in period $t$. The intermediate goods are produced using labor as an input according to the production function $y_{t}(j)=n_{t}(j)$, where $n_{j, t}$ denotes the amount of labor hired by firm $j$ in period $t$.

While the final good is produced by a representative competitive firm, the intermediate goods are produced by monopolistically competitive firms. The intermediate goods firms face frictions in adjusting their prices and can only update their prices with probability $\theta$ per period. These firms are controlled by a risk-neutral manager who discounts future profits at rate $\beta$. Whatever profits are produced are paid out immediately to the households with each household receiving an equal share $D_{t}$. Households cannot trade their stakes in the firms.

Households trade a risk-free real bond with real interest rate $r_{t}$ between periods $t$ and $t+1$. Borrowing constraints prevent these households from taking negative bond positions. There is a stock of government debt outstanding with real face value $B$. The government raises tax 
revenue to finance interest payments on this debt. These taxes are collected by taxing households according to their labor productivity $z_{h, t}$. The tax paid by a household $h$ in period $t$ is $\tau_{t} \bar{\tau}\left(Z_{i t}\right)$. The government runs a balanced budget so as to maintain a stable level of debt in each period.

MNS analyze an experiment in which the monetary authority announces that the real interest rate will be lowered by 1 percent for a single quarter five years in the future. The real rate is maintained in all other quarters. Using the MNS calibration, we run a thought experiment to analyze the effects of uncertainty households may perceive about forward guidance: we assume that households believe that there is a $50 \%$ chance that the central bank will follow through on the rate decrease five years in the future and a $50 \%$ chance that there is no rate change in five years.

Figure 13 plots the response of output to this shock in our extended MNS model, as well as in the complete and incomplete markets versions of the MNS model. The response of output under complete markets is a step function: Output immediately jumps up and remains at that elevated level for 20 quarters before returning to steady state. Consistent with MNS, output has a smaller initial response and is substantially smaller in the incomplete markets model than under complete markets, even in the period right before the interest rate decrease. This is because households trade off the cost of a lower buffer stock (more exposure to future income shocks) with the gains from intertemporal substitution, since they are no longer fully insured against all shocks as they would be with complete markets. In our experiment, when there is uncertainty about whether the rate decline promised under forward guidance will actually materialize, households discount the promise. This results in a muted effect of forward guidance, both at the outset and for the response in the period before quarter 20. In addition, households' risk aversion implies that, by Jensen's inequality, uncertainty about future interest rates further depresses the stimulating effects of the announcement. ${ }^{28}$

Thus, consistent with our empirical findings, a theoretical argument can be made that forward guidance has less power to stimulate the economy when households perceive some uncertainty about whether the promised rate cut will materialize.

\footnotetext{
${ }^{28}$ This effect is quantitatively small under the MNS calibration. This second-order Jensen's inequality effect (that further reduces output) is counteracted by a smaller redistribution effect: the interest rate shock leads to a redistribution of wealth away from households with high marginal propensities to consume and toward households with low marginal propensities to consume, which lowers aggregate demand and output; this effect is significantly smaller with our assumption in our experiment.
} 


\section{Conclusion}

We develop new measures of monetary policy uncertainty: uncertainty that the public perceives about Federal Reserve policy actions and their consequences. We compare these new measures to existing proxies and argue that there are good reasons to prefer ours, especially over medium term horizons such as FOMC meeting intervals. Empirically, we note for example that market-based measures were well subdued-close to zero-during the ZLB while ours were elevated and fluctuating. Conceptually, differences exist between our measure and the market-based indicators. In theory, the latter reflect the average perception of individuals participating in options markets. Our news-based index reflects the average opinion of people reading newspapers (assuming that newspapers reflect the readership). Since relatively few households participate in the options markets, the prices in these markets may not be particularly representative. In addition, in market-based indicators the perceived degree of uncertainty is contaminated with time-varying risk aversion and state-dependent marginal utility. ${ }^{29}$ Although we acknowledge (and try to control for) the potential state-dependency in newspaper coverage of central bank actions, we believe that our index is a preferable measure of monetary policy uncertainty, at least over the sample period and for the frequency we study.

We examine transmission of monetary policy uncertainty, showing that greater uncertainty has contractionary effects. Positive shocks to monetary policy uncertainty raise credit costs and lower output with about the same dynamic pattern as do identified contractionary monetary policy shocks such as GK's that are regarded as standard in the literature. The magnitude of estimated effects is at least as large as, if not larger than, those of monetary policy shocks. These results are robust to alternative measures of monetary policy uncertainty (Appendix F). Consistent with this, we make a simple theoretical argument why forward guidance could be less stimulative when households perceive some uncertainty about whether promised rate cuts will materialize.

Our findings are in line with others in the literature that illustrate negative economic effects of uncertainty shocks. Our analysis suggests that if policy rate normalization is successful in alleviating the public's uncertainty regarding monetary policy, that can help neutralize the

\footnotetext{
${ }^{29}$ The market-based measures are presumed to reflect the price individuals are willing to pay for insurance against future policy rate fluctuations. Willingness to substitute resources from one possible future to another depends on the relative scarcity of resources in those futures. Therefore, a household may be willing to pay a lot to insure against the possibility of a rate increase even if the household sees the outcome as highly unlikely.
} 
contractionary effects of the rate increases themselves.

\section{References}

[1] Acosta, Miguel 2015. "FOMC Responses to Calls for Transparency," Finance and Economics Discussion Series 2015-060, Board of Governors of the Federal Reserve System.

[2] Akkaya, Yildiz, Refet S. Gurkaynak, Burcin Kisacikoglu, and Jonathan H. Wright 2015. "Forward Guidance and Asset Prices," working paper, Johns Hopkins University.

[3] Angrist, Joshua D., and Alan B. Krueger. 2001. "Instrumental Variables and the Search for Identification: From Supply and Demand to Natural Experiments." Journal of Economic Perspectives, 15(4): 69-85.

[4] Azzimonti, M. 2017. "Partisan Confict and Private Investment," Journal of Monetary Economics, Forthcoming.

[5] Bachmann, R., S. Elstner, and E. Sims 2013. "Uncertainty and Economic Activity: Evidence from Business Survey Data," American Economic Journal: Macroeconomics, 5(2), 217-249.

[6] Bachmann, R., and G. Moscarini 2012. "Business Cycles and Endogenous Uncertainty," Yale University working paper.

[7] Baker, Scott, Nicholas Bloom, and Steven J. Davis, 2016. "Measuring Economic Policy Uncertainty," The Quarterly Journal of Economics 131, 1593-1636.

[8] Bauer, M. D., 2012. "Monetary Policy and Interest Rate Uncertainty," Federal Reserve Board San Francisco Economic Letter 2012-38.

[9] Bernanke, Ben S, 2015. The Courage to Act: A Memoir of a Crisis and its Aftermath. W.W. Norton and Company, New York.

[10] Bianchi, F., Melosi, L. 2016. "Modeling the Evolution of Expectations and Uncertainty in General Equilibrium," International Economic Review, 57(2), 717-756.

[11] Bianchi, Francesco, and Leonardo Melosi, 2017. "Constrained Discretion and Central Bank Transparency," Review of Economics and Statistics, forthcoming.

[12] Bloom, N. 2009. "The Impact of Uncertainty Shocks," Econometrica, 77(3), 623-685.

[13] Boukus, Ellyn, and Rosenberg, Joshua. 2006. "The information content of FOMC minutes," Federal Reserve Bank of New York.

[14] Brainard, Lael, 2017. "Monetary Policy in a Time of Uncertainty," Brookings Institution, Washington, D.C. January 17, 2017.

[15] Caldara, Dario, and Matteo Iacoviello (2017), "Measuring Geopolitical Risk," unpublished paper, Board of the Governors of the Federal Reserve Board, September 2016, available at https://www2.bc.edu/matteoiacoviello/gpr_files/GPR_PAPER.pdf

[16] Campbell, J.R., C.L. Evans, J.D. Fisher, and A. Justiniano, 2012. "Macroeconomic Effects of Federal Reserve Forward Guidance," Brookings Papers on Economic Activity, Spring, pp. $1-54$. 
[17] Campbell, J.R., J.D. Fisher, A. Justiniano, and L. Melosi, 2016. "Forward Guidance and Macroeconomic Outcomes since the Financial Crisis," Federal Reserve Bank of Chicago, WP 2016-07.

[18] Carlson, J. B., Craig, B. R., and Melick, W. R., 2005. "Recovering Market Expectations of FOMC Rate Changes with Options on Federal Funds Futures," Journal of Futures Markets, $25,1203-1242$.

[19] Carlston, Benjamin, and Marcelo Ochoa, 2016. "Macroeconomic Announcements and Investors Beliefs at the Zero Lower Bound," working paper, Federal Reserve Board.

[20] Creal, Drew D., and Jing C. Wu, 2016. "Monetary Policy Uncertainty and Economic Fluctuations," International Economic Review, forthcoming.

[21] Cukierman, Alex, and Allan H. Meltzer. 1986. "A Theory of Ambiguity, Credibility, and Inflation under Discretion and Asymmetric Information," Econometrica 54, 1099-1128.

[22] Davis, A. K., J. Piger, and L. M. Sedor. 2012. "Beyond The Numbers: An Analysis Of Optimistic And Pessimistic Language In Earnings Press Releases," Contemporary Accounting Research, 29, 845868.

[23] Demers, E., and C. Vega, 2010. "Soft Information In Earnings Announcements: News Or Noise?" Working Paper, INSEAD.

[24] Ehrmann, M., Smets, F. 2003. "Uncertain Potential Output: Implications for Monetary Policy," Journal of Economic Dynamics and Control, 27(9), 1611-1638.

[25] Ehrmann, Michael, and Fratzscher, Marcel. 2007. "Communication by central bank committee members: different strategies, same effectiveness?" Journal of Money, Credit and Banking, 39(2-3), 509541.

[26] Emmons, W. R., Lakdawala, A. K., and Neely, C. J., 2006. "What Are the Odds? OptionBased Forecasts of FOMC Target Changes," Federal Reserve Bank of St. Louis Review, November/December 2006, 88, 543-61.

[27] Engen, Eric M., Thomas T. Laubach, and David Reifschneider. 2015. "The Macroeconomic Effects of the Federal Reserve's Unconventional Monetary Policies," Finance and Economic Discussion Series 2015-005. Board of Governors of the Federal Reserve System.

[28] Engelberg, J. E. , 2008. "Costly Information Processing: Evidence From Earnings Announcements," Working Paper, University of North Carolina.

[29] Eusepi, S., Preston, B. 2010. "Central Bank Communication and Expectations Stabilization," American Economic Journal: Macroeconomics, 2(3), 235-271.

[30] Faust, J., and L. E. O. Svensson. 1999. "The Equilibrium Degree of Transparency and Control in Monetary Policy," Journal of Money, Credit, and Banking.

[31] Faust, J., and L. E. O. Svensson. 2001. "Transparency and Credibility: Monetary Policy with Unobservable Goals," International Economic Review, 42(2).

[32] Feldman, R., S. Govindaraj, J. Livnat, and B. Segal, 2010. "Managements Tone Change, Post Earnings Announcement Drift And Accruals," Review of Accounting Studies 15, 915953. 
[33] Fernandez-Villaverde, J., P. Guerron-Quintana, K. Kuester, and J. Rubio-Ramirez 2015. "Fiscal Volatility Shocks and Economic Activity," forthcoming in American Economic Review.

[34] Fernandez-Villaverde, J., P. Guerron-Quintana, J. F. Rubio-Ramirez, and M. Uribe 2011. "Risk Matters: The Real Effects of Volatility Shocks," American Economic Review, 101(6), 2530-61.

[35] Fischer, S. 2017. "Monetary Policy Expectations and Surprises", Columbia University, https://www.federalreserve.gov/newsevents/speech/fischer20170417a.htm

[36] Goodfriend, Marvin. 1986, "Monetary Mystique: Secrecy and Central Banking," Journal of Monetary Economics, 17, 63-92.

[37] Hoberg, Gerard, and Gordon Phillips. 2010. "Product Market Synergies and Competition in Mergers and Acquisitions: A Text-Based Analysis," Review of Financial Studies 23(10): 37733811.

[38] Husted, L., J. Rogers, and B. Sun, 2016a. "Measuring Monetary Policy Uncertainty: The Federal Reserve January 1986 to January 2016," Federal Reserve Board, https://www.federalreserve.gov/econresdata/notes/ifdp-notes/2016/measuring-monetarypolicy-uncertainty-the-federal-reserve-january-1985-january-2016-20160411.html

[39] Husted, L., J. Rogers, and B. Sun, 2016b. "Measuring Cross-Country Monetary Policy Uncertainty," Federal Reserve Board, https://www.federalreserve.gov/econresdata/notes/ifdpnotes/2016/measuring-cross-country-monetary-policy-uncertainty-20161123.html

[40] Jurado, Kyle, Sydney C. Ludvigson and Serena Ng. 2015. "Measuring Uncertainty." American Economic Review, 105(3): 1177-1216.

[41] Justiniano, A., and G. Primiceri. 2008. "Time-Varying Volatility of Macroeconomic Fluctuations," American Economic Review, 98(3), 604-641.

[42] Levin, A., Wieland, V., Williams, J. 2003. "The Performance of Forecast-Based Monetary Policy Rules Under Model Uncertainty," American Economic Review, 93(3), 622-645.

[43] Loughran, T., and B. McDonald, 2011. "When Is a Liability Not a Liability? Textual Analysis, Dictionaries, and 10-Ks," Journal of Finance 66, 3565.

[44] Ludvigson S., S. Ma, and S. Ng, 2016. "Uncertainty and Business Cycles," Working Paper, New York University and Columbia University.

[45] McKay, A., E. Nakamura, and J. Steinsson, 2016. "The Power of Forward Guidance Revisited," American Economic Review, 106(10), 3133-3158.

[46] Meade, Ellen E, and Miguel Acosta, 2015. "Hanging on every word: Semantic analysis of the FOMC's postmeeting statement," FEDS Notes, Federal Reserve Board

[47] Meade, Ellen E, and Stasavage, David. 2008. "Publicity of Debate and the Incentive to Dissent: Evidence from the US Federal Reserve," The Economic Journal, 118(528), 695717.

[48] Nakamura, E., D. Sergeyev, and J. Steinsson, 2014 . "Growth-Rate and Uncertainty Shocks in Consumption: Cross-Country Evidence," Columbia University working paper. 
[49] Ramey, Valerie, 2015. "Macroeconomic Shocks and Their Propagation," Handbook of Macroeconomics.

[50] Rogers, John, Chiara Scotti, and Jonathan Wright, 2016. "Unconventional Monetary Policy and International Risk Premia," International Finance Discussion Paper 1172, Federal Reserve Board, https://www.federalreserve.gov/econresdata/ifdp/2016/files/ifdp1172.pdf

[51] Romer, Christina D., and David H. Romer, 2004. "A New Measure of Monetary Shocks: Derivation and Implications," American Economic Review, 94(4), pp. 1054-1084.

[52] Rudebusch, G. 2001. "Is the Fed too Timid? Monetary Policy in an Uncertain World," Review of Economics and Statistics, 83(2), 203-217.

[53] Rudebusch, G. 2002. "Assessing Nominal Income Rules for Monetary Policy with Model and Data Uncertainty," Economic Journal, 112(479), 402-432.

[54] Scotti, Chiara, 2013. "Surprise and Uncertainty Indexes: Real-Time Aggregation of RealActivity Macro Surprises," International Finance Discussion Papers 1093. Board of Governors of the Federal Reserve System.

[55] Schonhardt-Bailey, Cheryl. 2013. "Deliberating American Monetary Policy: A Textual Analysis," The MIT Press.

[56] Sims, Christopher J, 1980. "Macroeconomics and Reality," Econometrica.

[57] Stock, J., and M. Watson 2012. "Disentangling the Channels of the 2007-2009 Recession," Brookings Papers on Economic Activity, pp. 81-135.

[58] Stock J and Yogo M. 2005. "Testing for Weak Instruments in Linear IV Regression. In: Andrews DWK Identification and Inference for Econometric Models. Identification and Inference for Econometric Models," New York: Cambridge University Press, pp. 80-108.

[59] Swanson, E. T., 2006. "Have Increases in Federal Reserve Transparency Improved Private Sector Interest Rate Forecasts?" Journal of Money, Credit and Banking, 38, 791-819.

[60] Shoag, Daniel and Stan Veuger. 2015. "Uncertainty and the geography of the great recession," Harvard Kennedy School mimeo.

[61] Tetlock, P. C., 2007. "Giving Content To Investor Sentiment: The Role Of Media In The Stock Market," Journal of Finance 62, 11391168.

[62] Tetlock, P. C., M. Saar-Tsechansky, and S. Macskassy, 2008. "More Than Words: Quantifying Language To Measure Firms' Fundamentals," Journal of Finance 63, 14371467.

[63] Thornton, D. L. and Wheelock, D. C., 2014. "Making Sense of Dissents: A History of FOMC Dissents," Federal Reserve Bank of St. Louis Review, 96(3), 213-227.

[64] Woodford, Michael, 2013. "Forward Guidance by Inflation-Targeting Central Banks," Columbia University Working Paper. 
Table 1: Magnitude of MPU Shocks: Comparison Across Identifications

\begin{tabular}{|c|c|c|c|c|c|c|c|c|}
\hline & GK Paper & Updated GK & GK with MPU & Cholesky & $\begin{array}{c}\text { Sign } \\
\text { Restriction } \\
\end{array}$ & $\begin{array}{c}\text { External } \\
\text { Baseline MPU } \\
\end{array}$ & $\begin{array}{c}\text { Instrument } \\
\text { Human MPU }\end{array}$ & $\begin{array}{l}\text { Estimation } \\
\text { Baseline '94-'15 }\end{array}$ \\
\hline MPU (impact) & $\ldots$ & $\ldots$ & 5.80 & 36.60 & 37.30 & 36.60 & 36.60 & 36.60 \\
\hline Interest rate (impact) & 0.22 & 0.19 & 0.20 & -0.01 & 0.11 & 0.07 & 0.05 & 0.10 \\
\hline Month of max drop in IP & 23 & 30 & 30 & 17 & 28 & 21 & 21 & 21 \\
\hline IP at horizion 12 & -0.13 & -0.70 & -0.67 & -0.17 & -0.08 & -1.45 & -0.98 & -0.85 \\
\hline Max drop in CPI & -0.04 & -0.11 & -0.10 & -0.14 & -0.01 & -0.13 & -0.07 & -0.16 \\
\hline Month of max drop in CPI & 40 & 60 & 60 & 16 & 35 & 30 & 34 & 36 \\
\hline CPI at horizion 12 & 0.04 & 0.09 & 0.04 & -0.08 & -0.14 & -0.01 & -0.03 & -0.21 \\
\hline
\end{tabular}

Impulse responses under the different VAR identification schemes. The first two columns are from an identified monetary policy shock in the four-variable VAR of Gertler and Karadi (2015). In the third column, MPU is added to the GK model and impulse responses are to the GK monetary policy shock. The remaining columns are impulse responses to identified MPU shocks in the same five-variable VAR $\left[i p_{t}, c p i_{t}, m p u_{t}, i_{t}, e b p_{t}\right]$. All estimates are over 1985:1-2015:12, except the final column which is 1994:1-2015:12. 


\section{Table 2: Does FOMC Communication Influence MPU?}

\begin{tabular}{lcc}
\hline \hline & $(1)$ & $(2)$ \\
\hline Dissenting Votes $(t-1)$ & 71.6 & \\
Statement Persistence $(t-1)$ & $-41^{*}$ & $-37.5^{+}$ \\
& $(-2.11)$ & $(-1.95)$ \\
Statement/Minute Uncertainty & 597.8 & \\
& $(0.82)$ & \\
Financial Uncertainty & 148.8 & $164.5^{+}$ \\
& $(1.50)$ & $(1.71)$ \\
Macro Uncertainty & -151.8 & -170 \\
& $(-1.38)$ & $(-1.58)$ \\
Geopolitical Risk & $0.40^{* *}$ & $0.41^{* *}$ \\
& $(5.07)$ & $(5.32)$ \\
Member Turnover & 1.90 & \\
& $(0.32)$ & \\
Constant & 74.9 & 88 \\
& $(0.78)$ & $(0.93)$ \\
\hline Dummy 2008H2 & Yes & Yes \\
Chair Dummies & Yes & Yes \\
Adj. $R^{2}$ & 0.26 & 0.27 \\
Number of Observations & 128 & 128 \\
\hline \hline
\end{tabular}

Dependent variable: MPU at FOMC meeting interval, 1985-2015;

Dissenting Votes (1-meeting lag): percentage of dissenting votes in the previous meeting;

Statement Persistence (1-meeting lag): the similarity of statements between the previous and the current FOMC meeting (Acosta, 2015);

Statement/Minute Uncertainty: percentage of words meaning uncertainty in FOMC statments and minutes over the inter-meeting period;

Member Turnover: number of new members on the FOMC at the current meeting.

Macro Uncertainty: Jurado, Ludvigson, and Ng (2013) measure of Macroeconomic Uncertainty (12 month horizon);

Financial Uncertainty: Ludvigson, Ng, and Ma (2016) measure of financial uncertainty.

Geopolitical Risk Index: Caldara and Iacoviello (2017) measure of geopolitical conflict and terrorism based on news releases. 
Figure 1: Monetary Policy Uncertainty Index

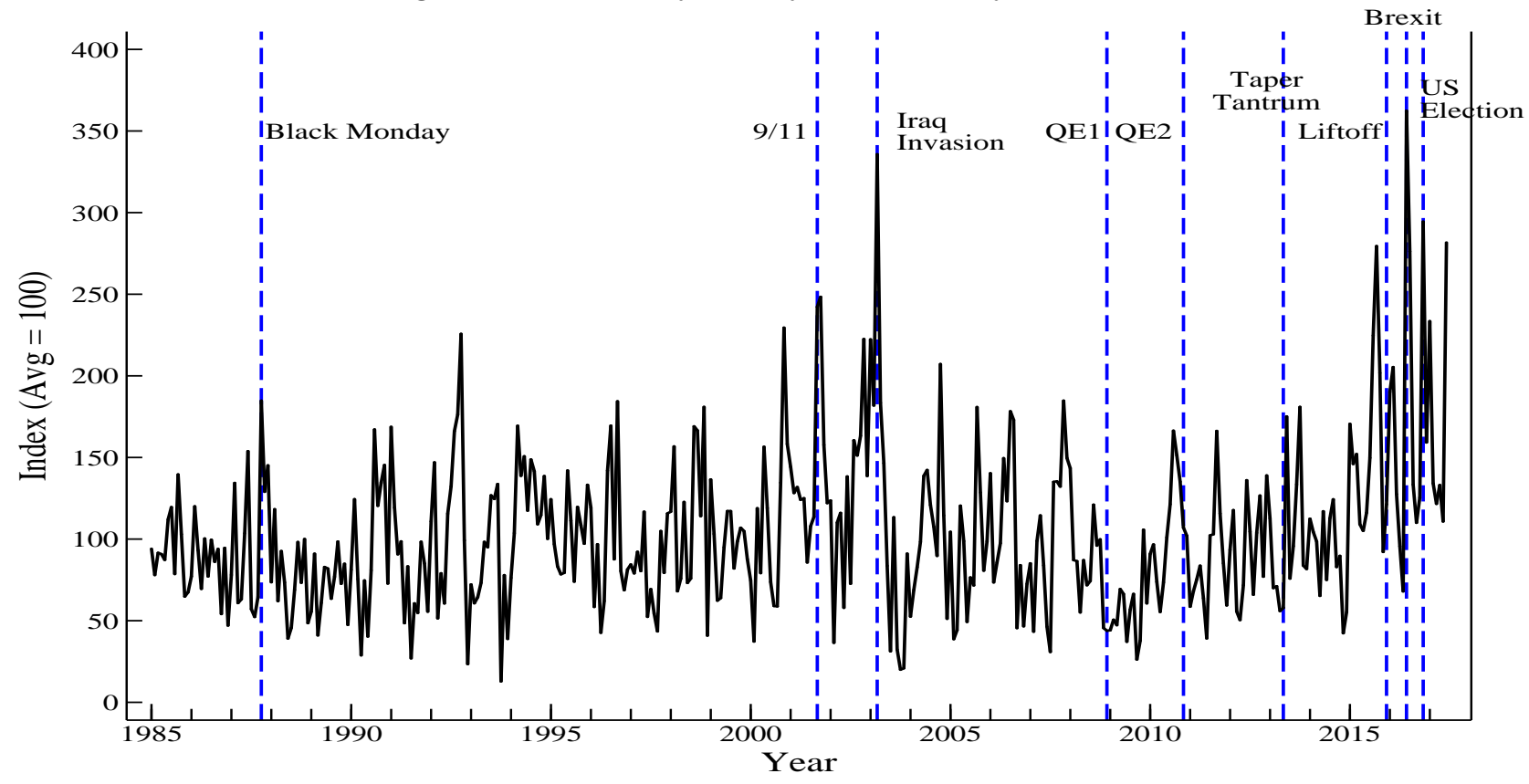

MPU index, monthly frequency (January 1985 - June 2017)

Figure 2: Human index vs. Computer index

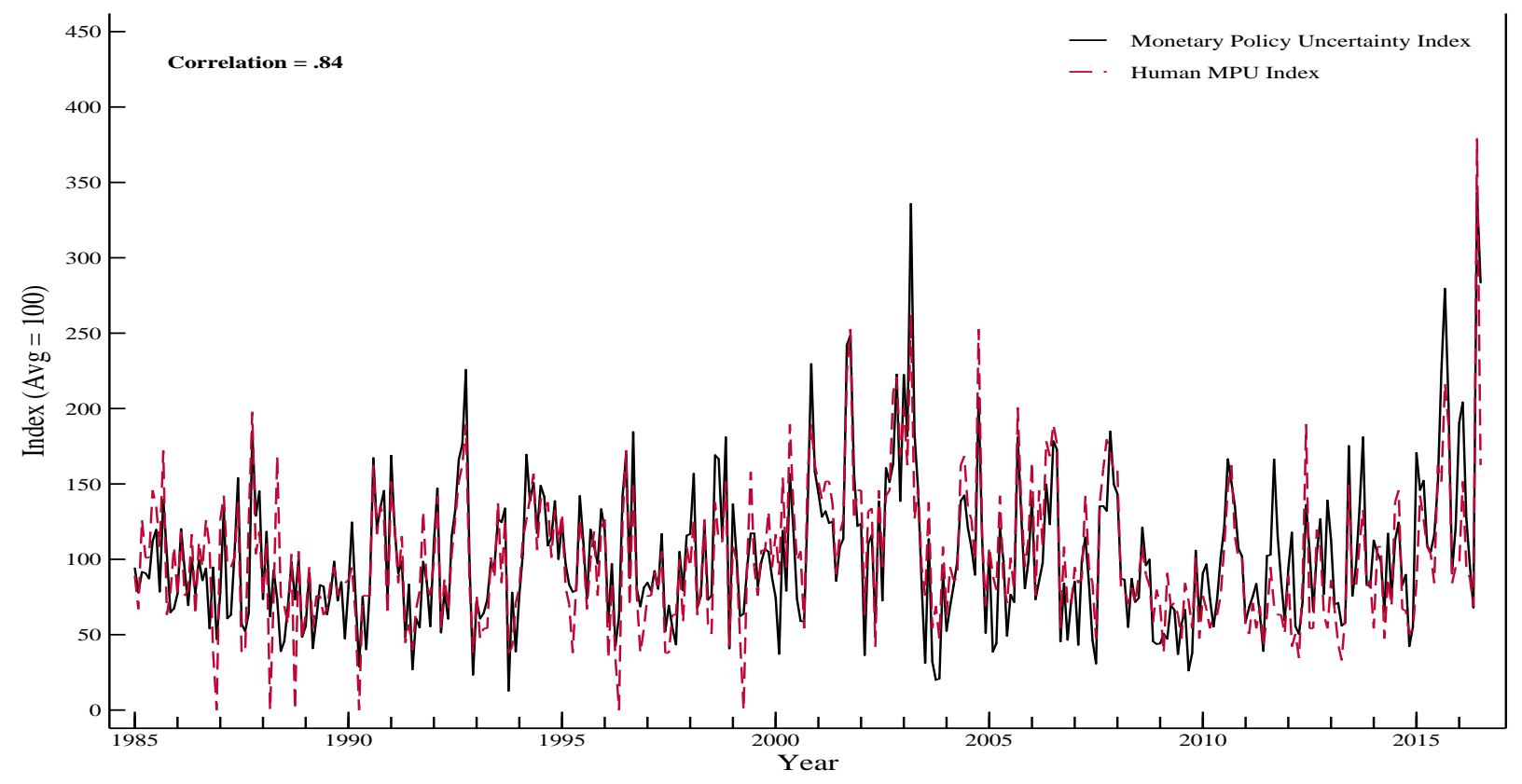

MPU index against human index 
Figure 3: Type I error rate

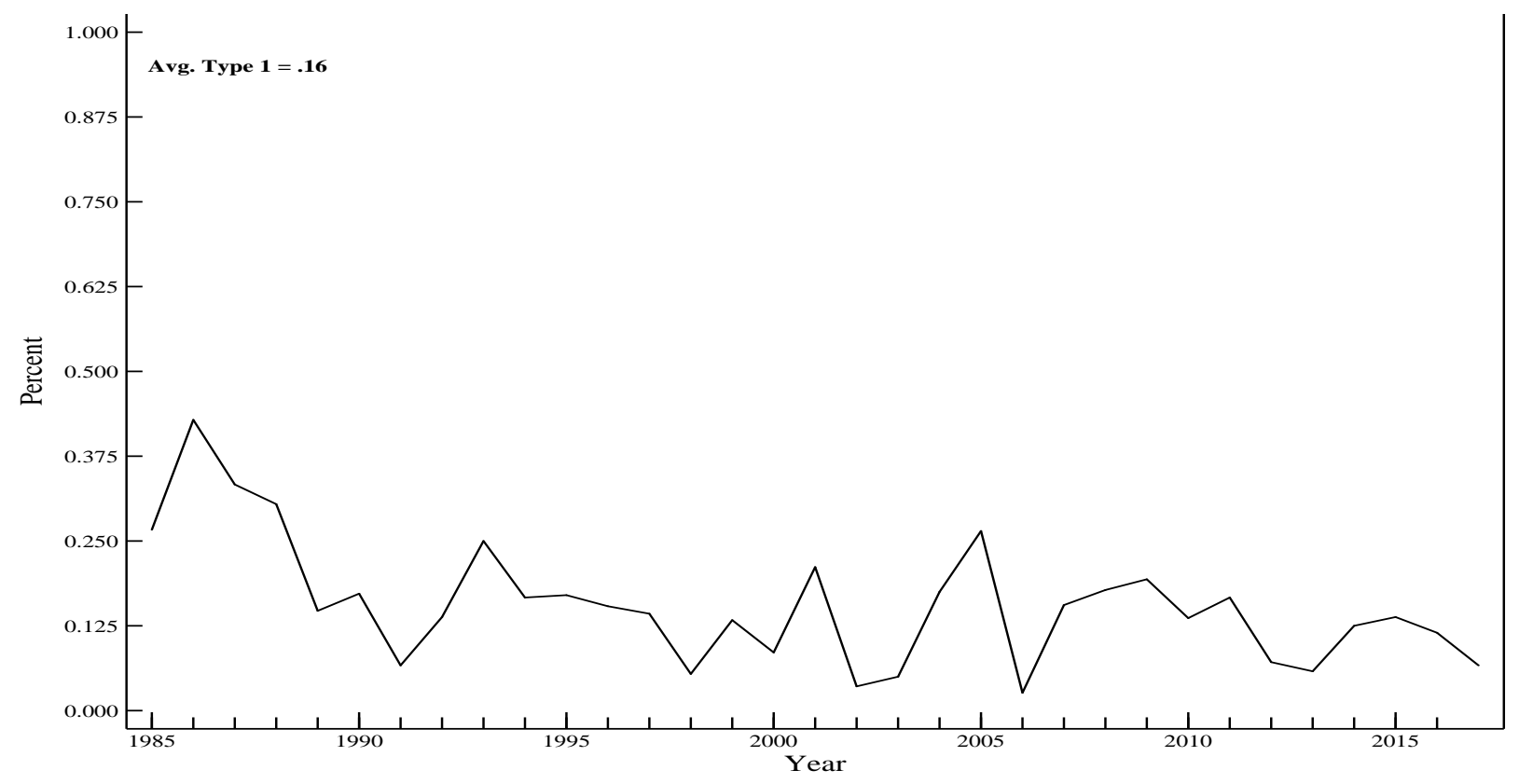

Type I error rate in MPU index

Figure 4: Type II error rate

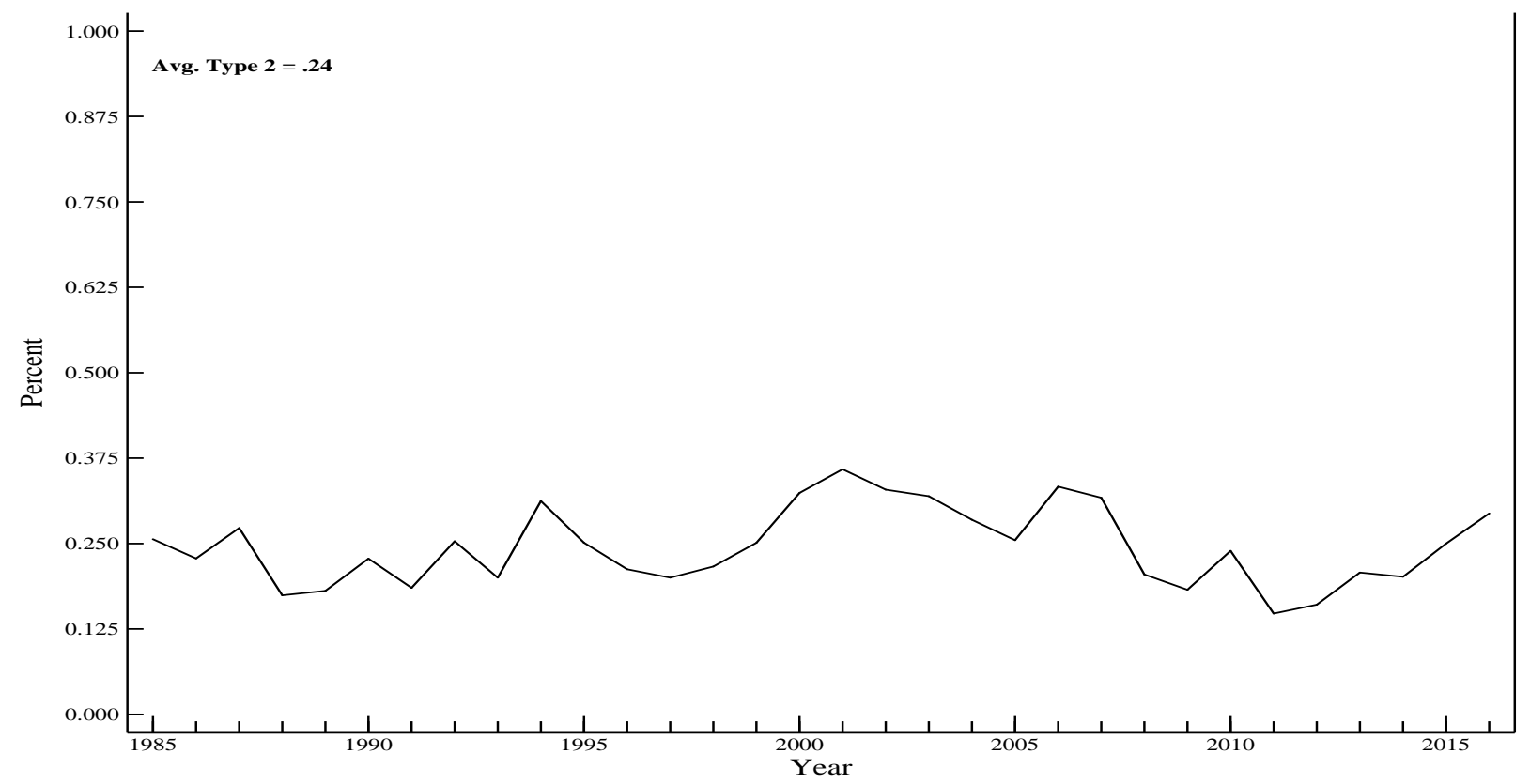

Type II error rate in MPU index 
Figure 5: Monetary Policy Shock, GK External Instruments Identification
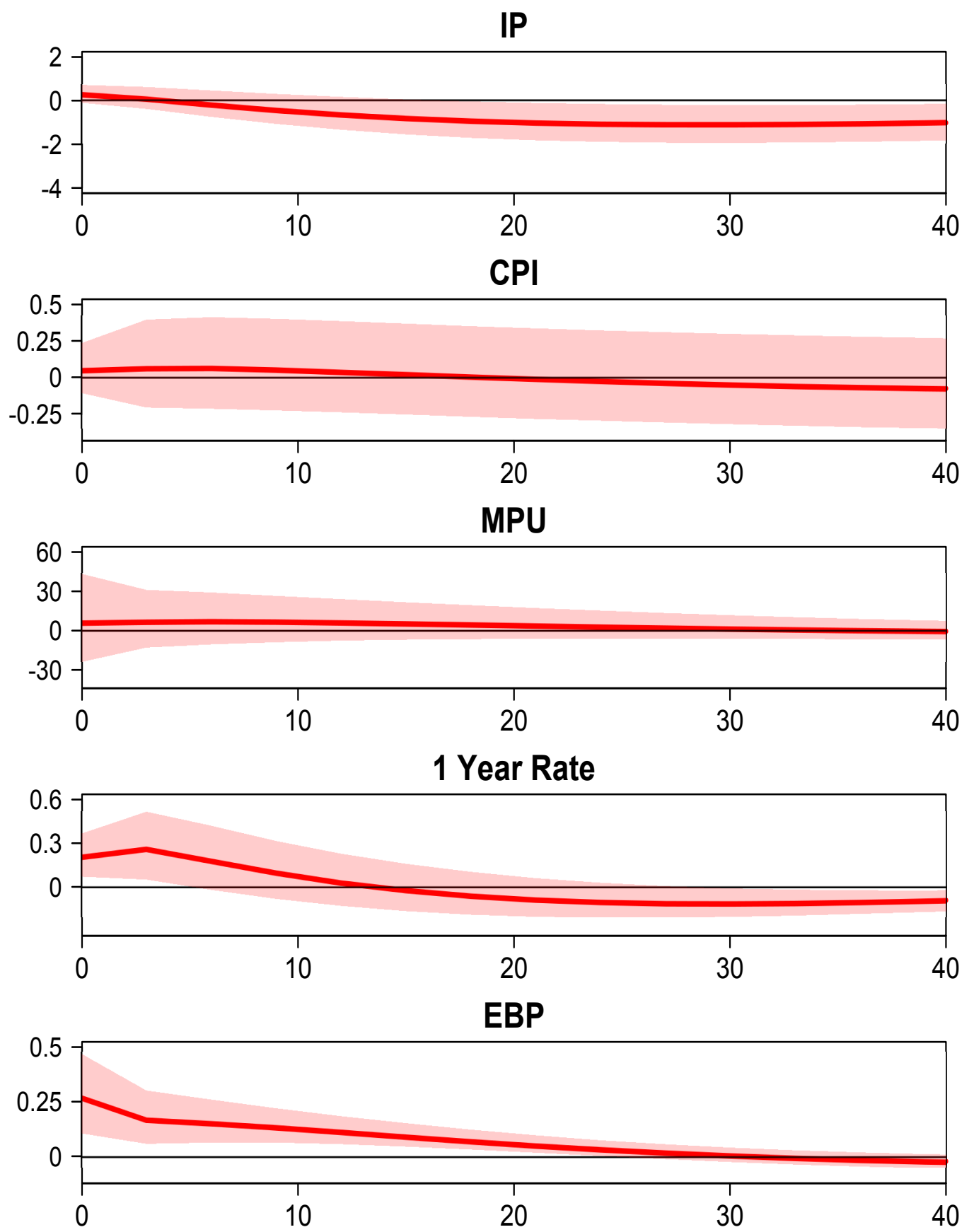

Impulse responses to a monetary policy shock, identified using external instruments. The VAR is Gertler and Karadi's (2015) four-variable model, supplemented with our baseline MPU, estimated over 1985:1-2015:12. Dashed lines represent 68 percent confidence bands. 
Figure 6: MPU Shock, Cholesky and Sign Restrictions
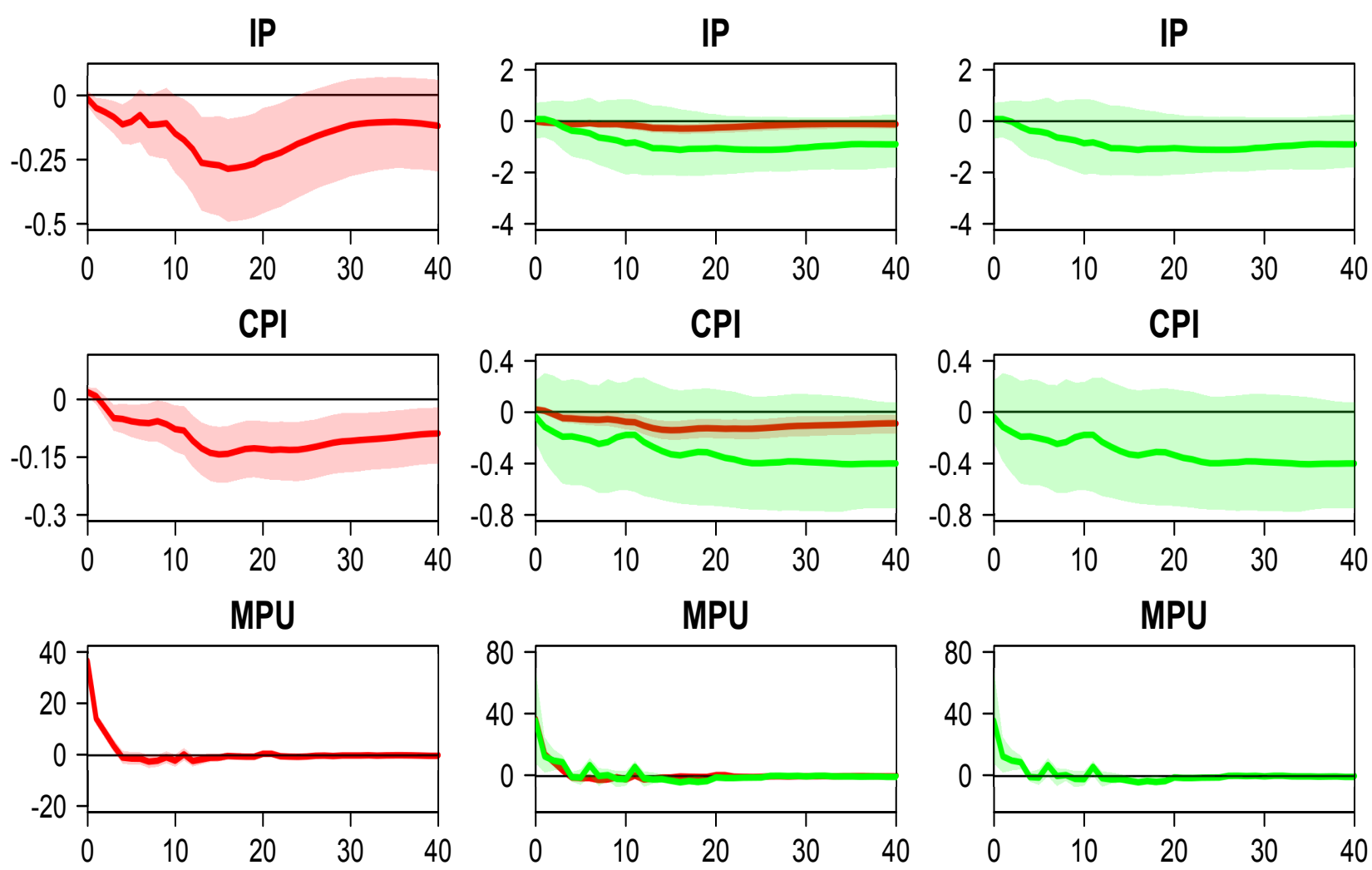

1 Year Rate

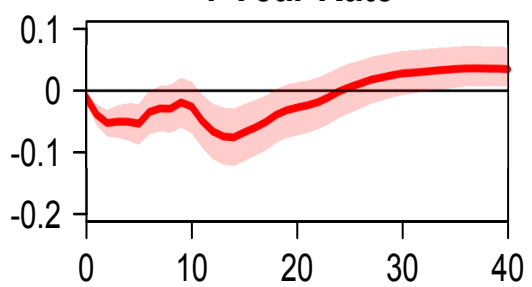

1 Year Rate

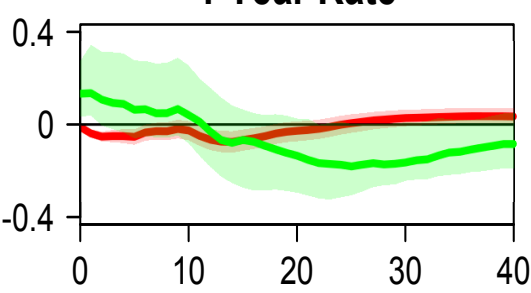

EBP

EBP
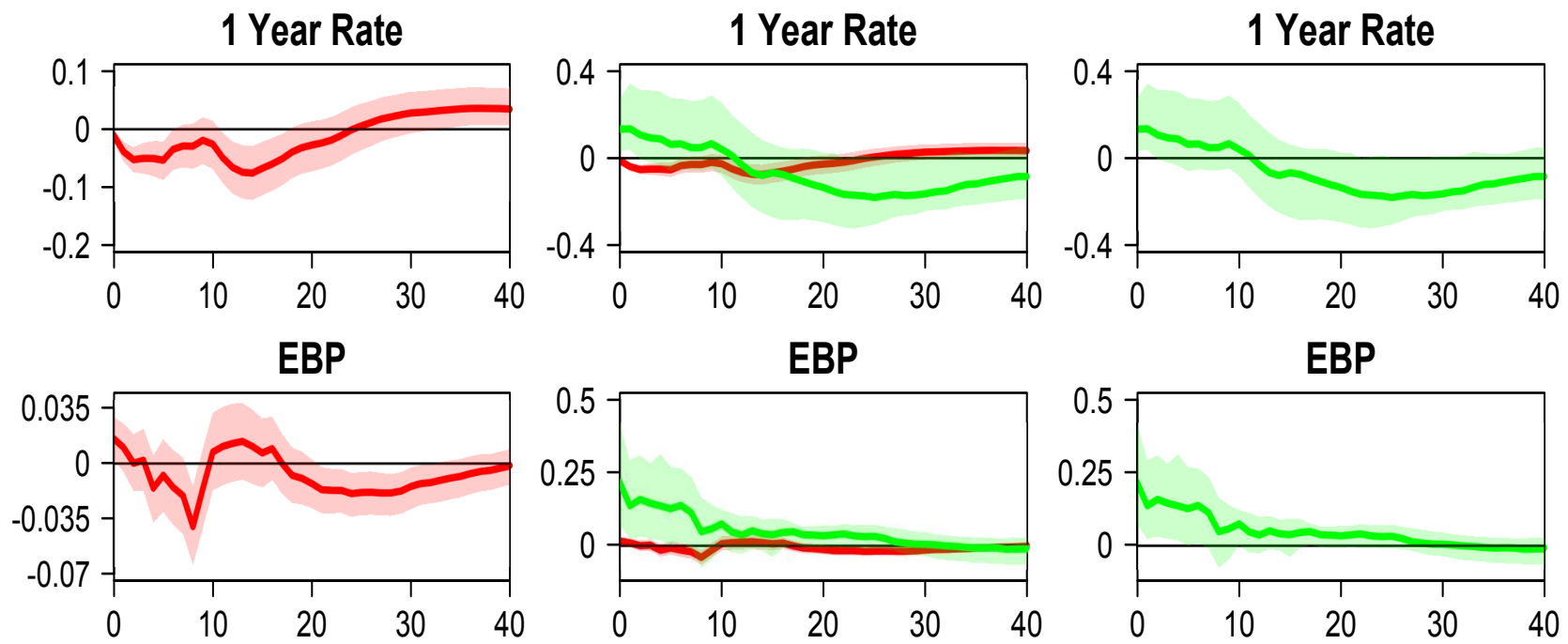

EBP

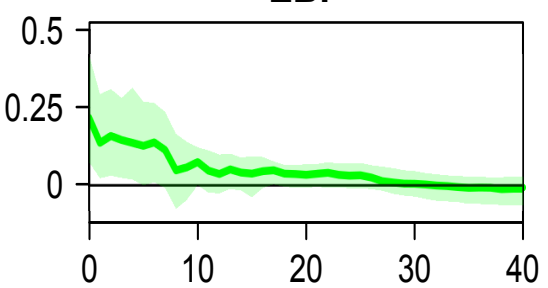

- Cholesky

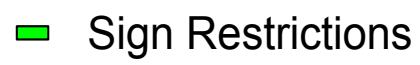

Impulse responses to an MPU shock. The left panels are for a Cholesky decomposition. The far right panels are the median, 16th and 84th percentile of the distributions for the sign restrictions case (MPU, interest rate and EBP rise on impact). The middle panels display the Cholesky and sign restriction cases together, absent confidence bands. 
Figure 7: MPU Shock, External Instruments
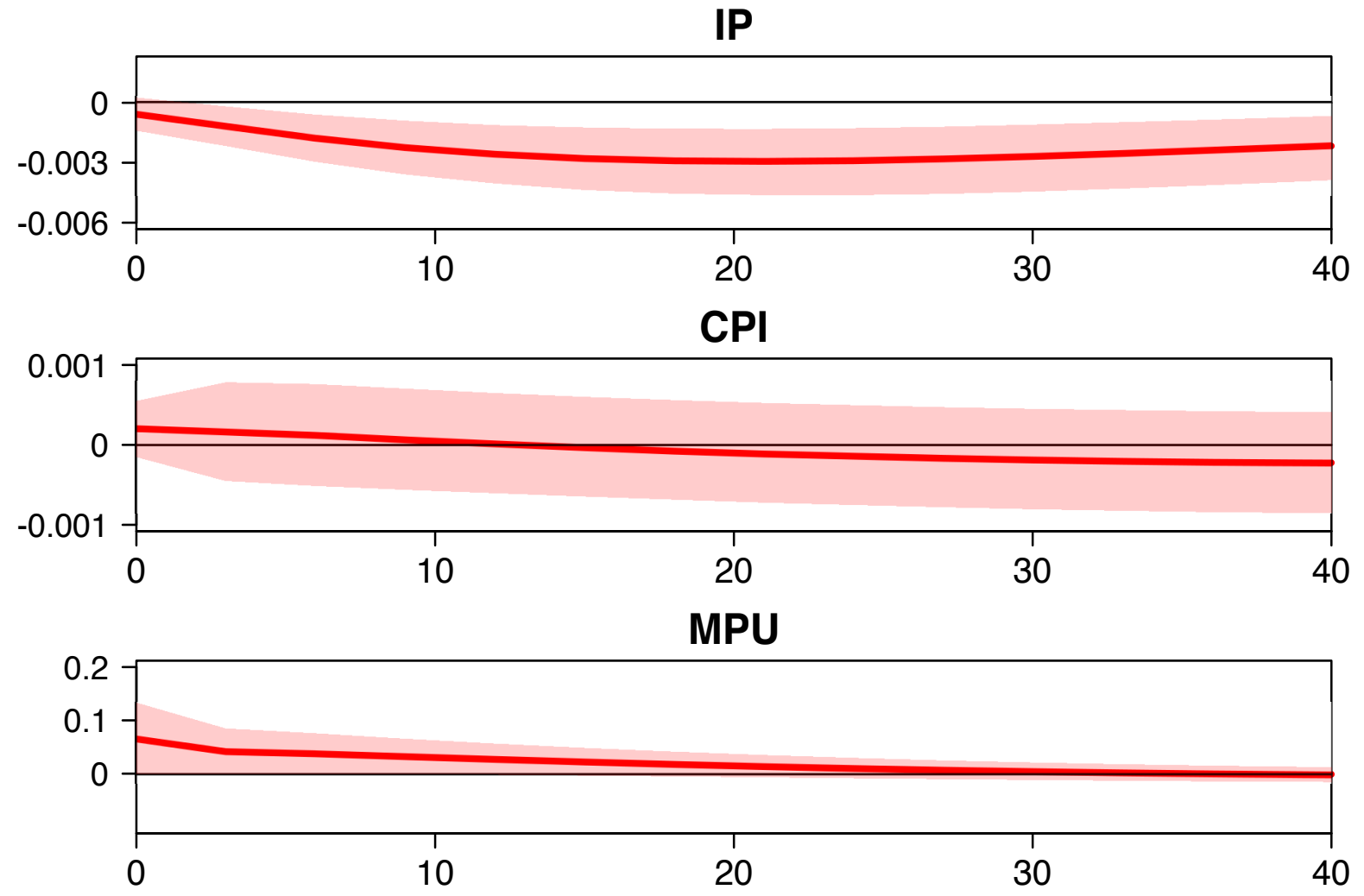

1 Year Rate
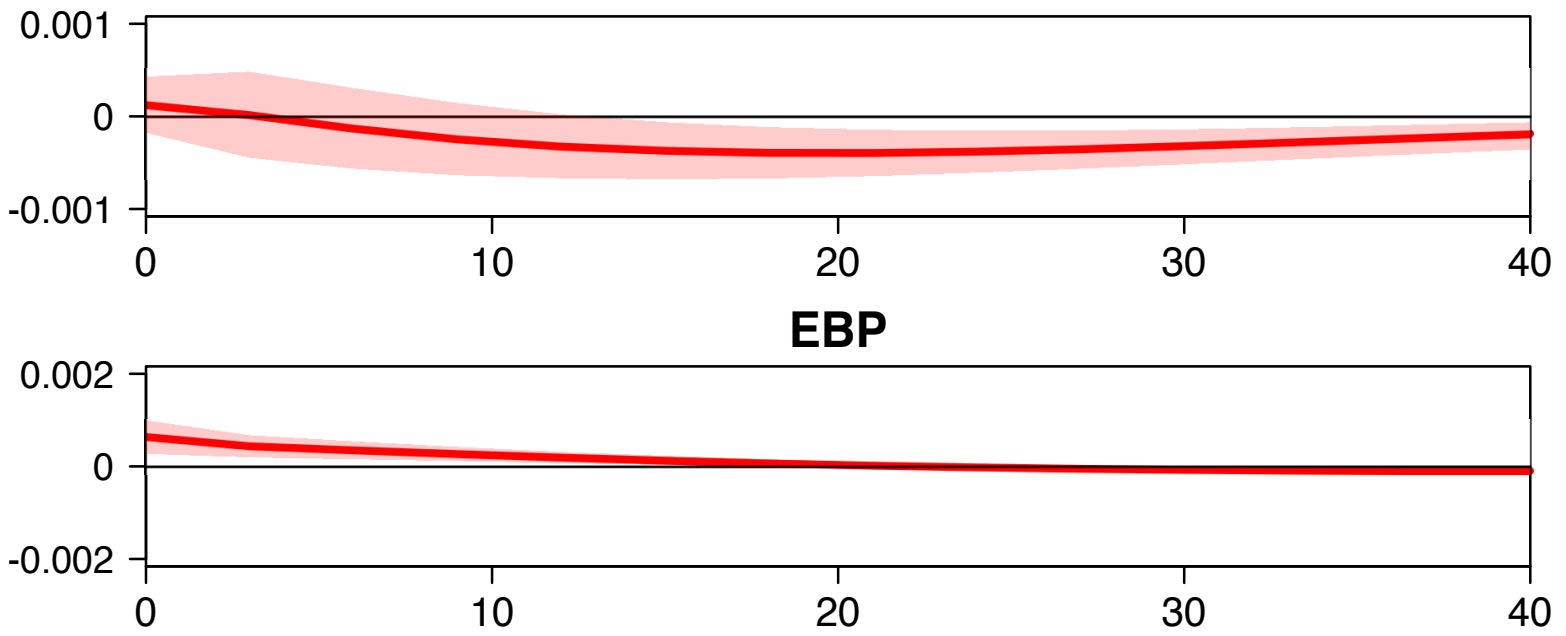

Impulse responses to an MPU shock, identified using external instruments. 


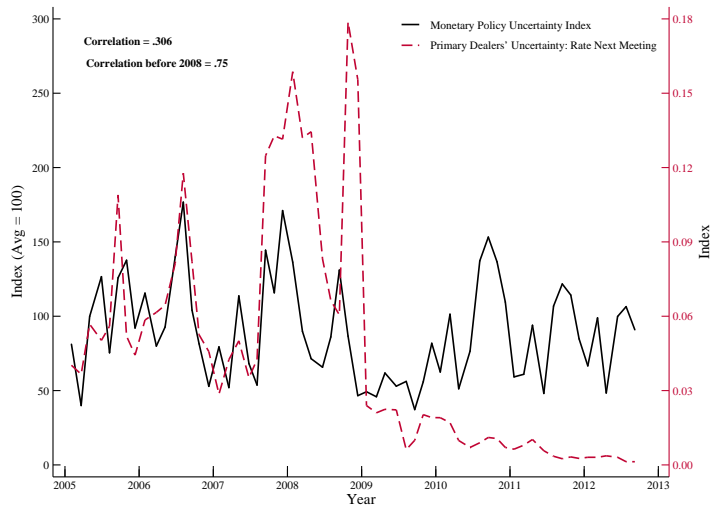

Figure 8: MPU vs. Survey (FFR) MPU index against uncertainty meast

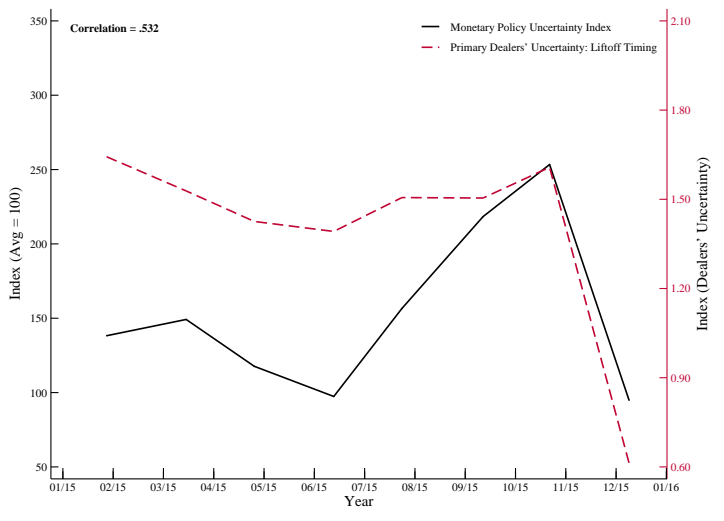

Figure 9: MPU vs. Survey (liftoff)

Figure 10: MPU index vs. Market-based Measure (1 year)

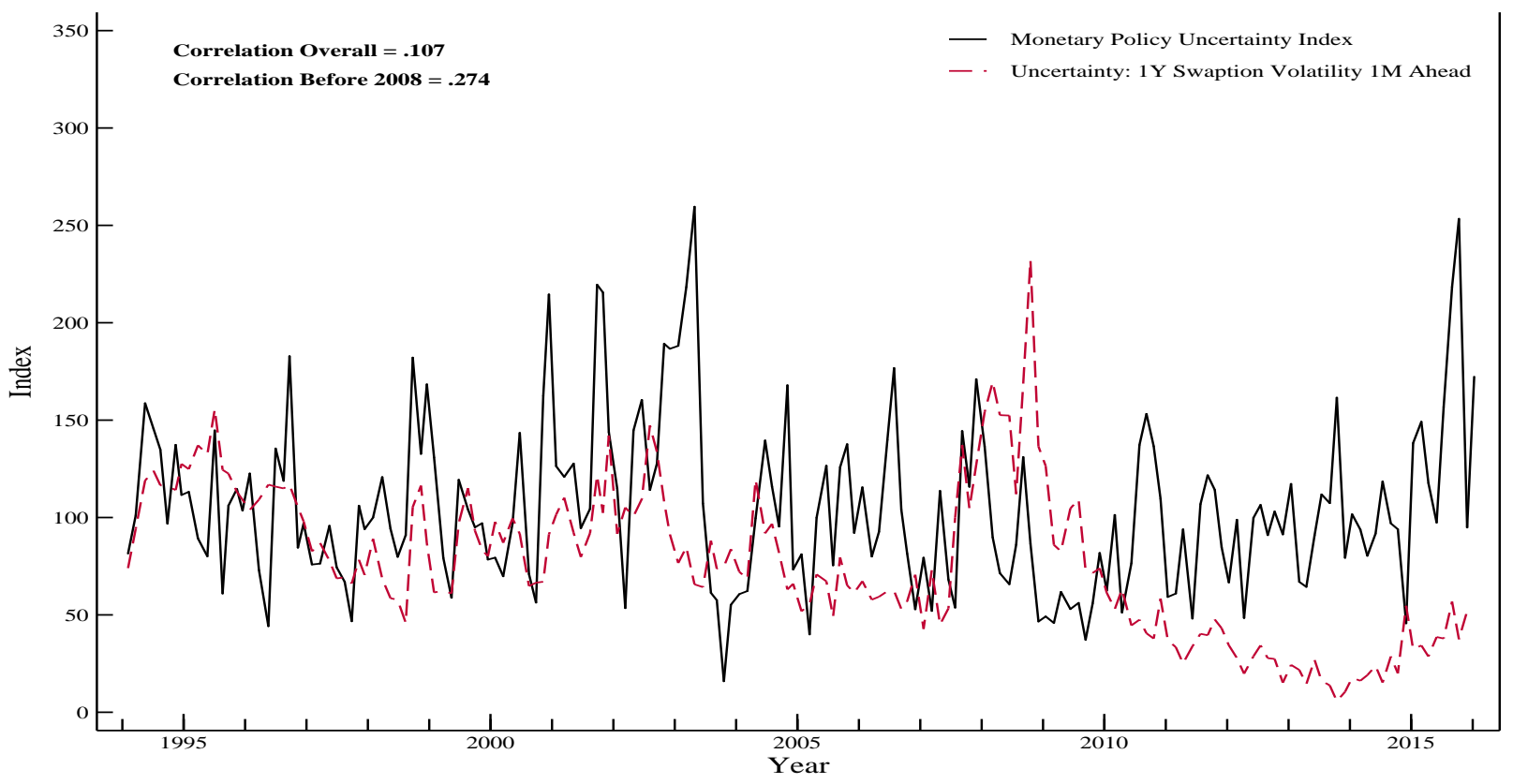

MPU index against swaptions volatility, from Carlston and Ochoa (2016) 
Figure 11: MPU Index vs. sub-category EPU

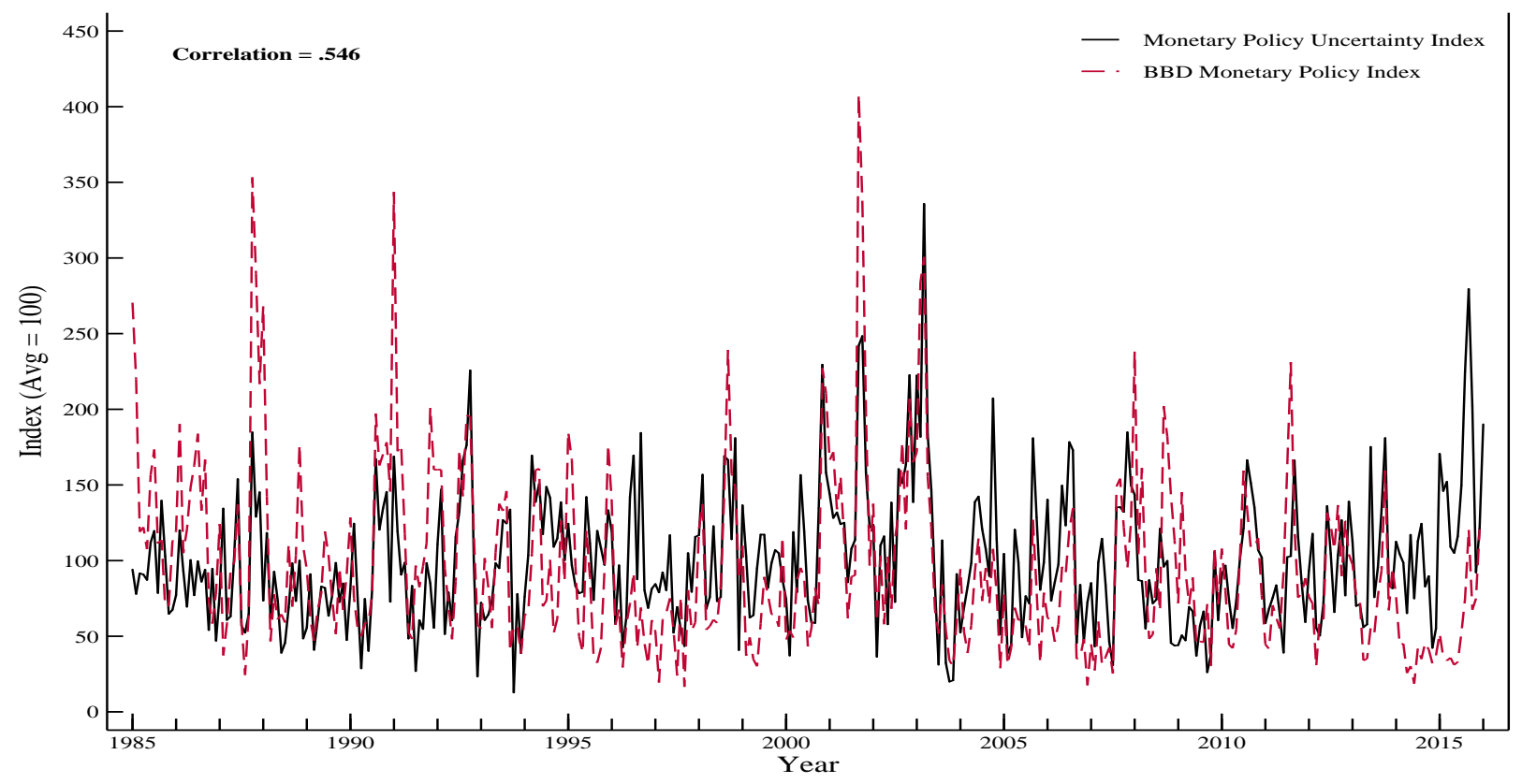

Baseline MPU index against monetary policy sub-index of Baker, Bloom, and Davis (2016).

Figure 12: MPU around FOMC Meetings

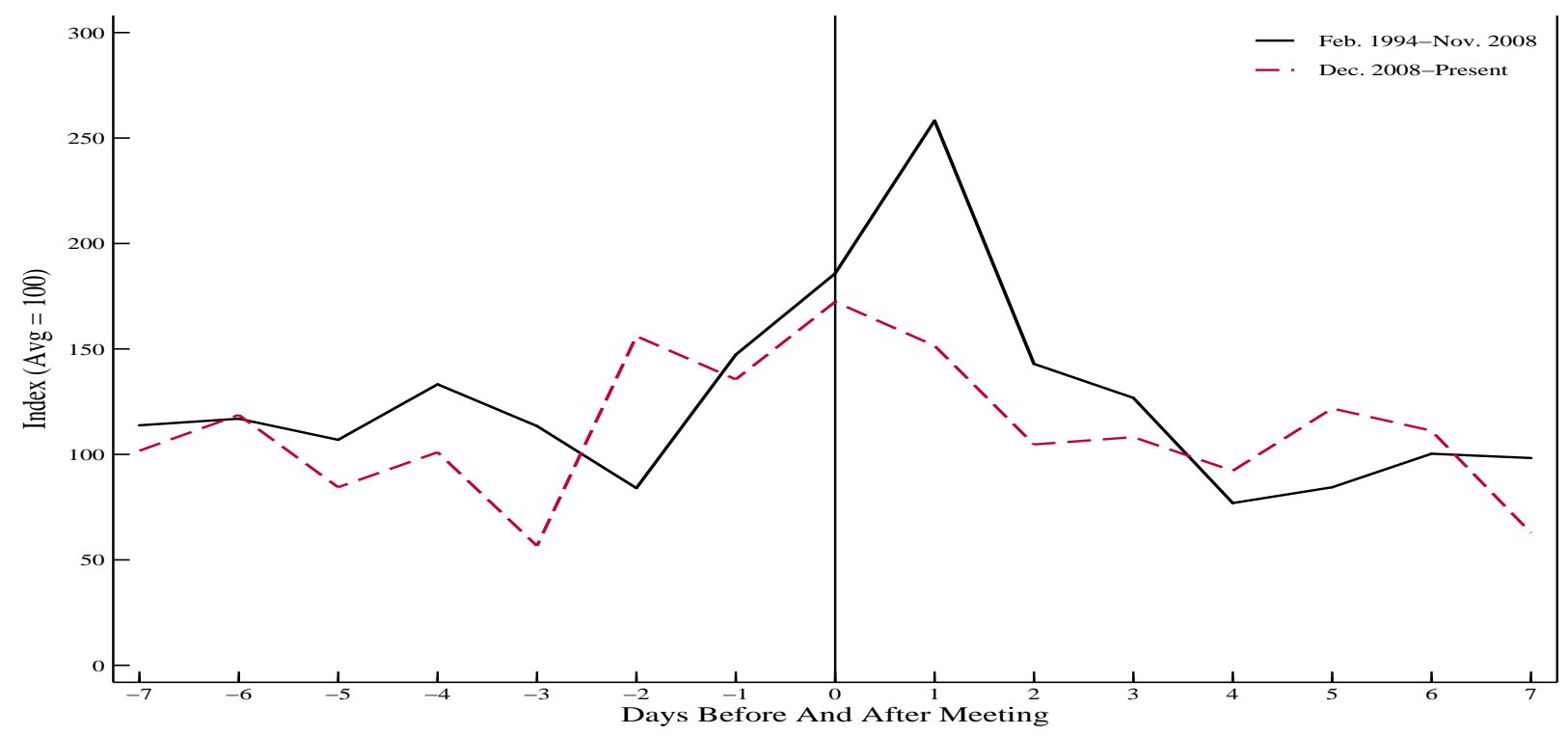

Daily MPU, before and after FOMC meetings. Average levels during two different sub-periods. 
Figure 13: Response of Output to 50bps Rate Cut in Quarter 20

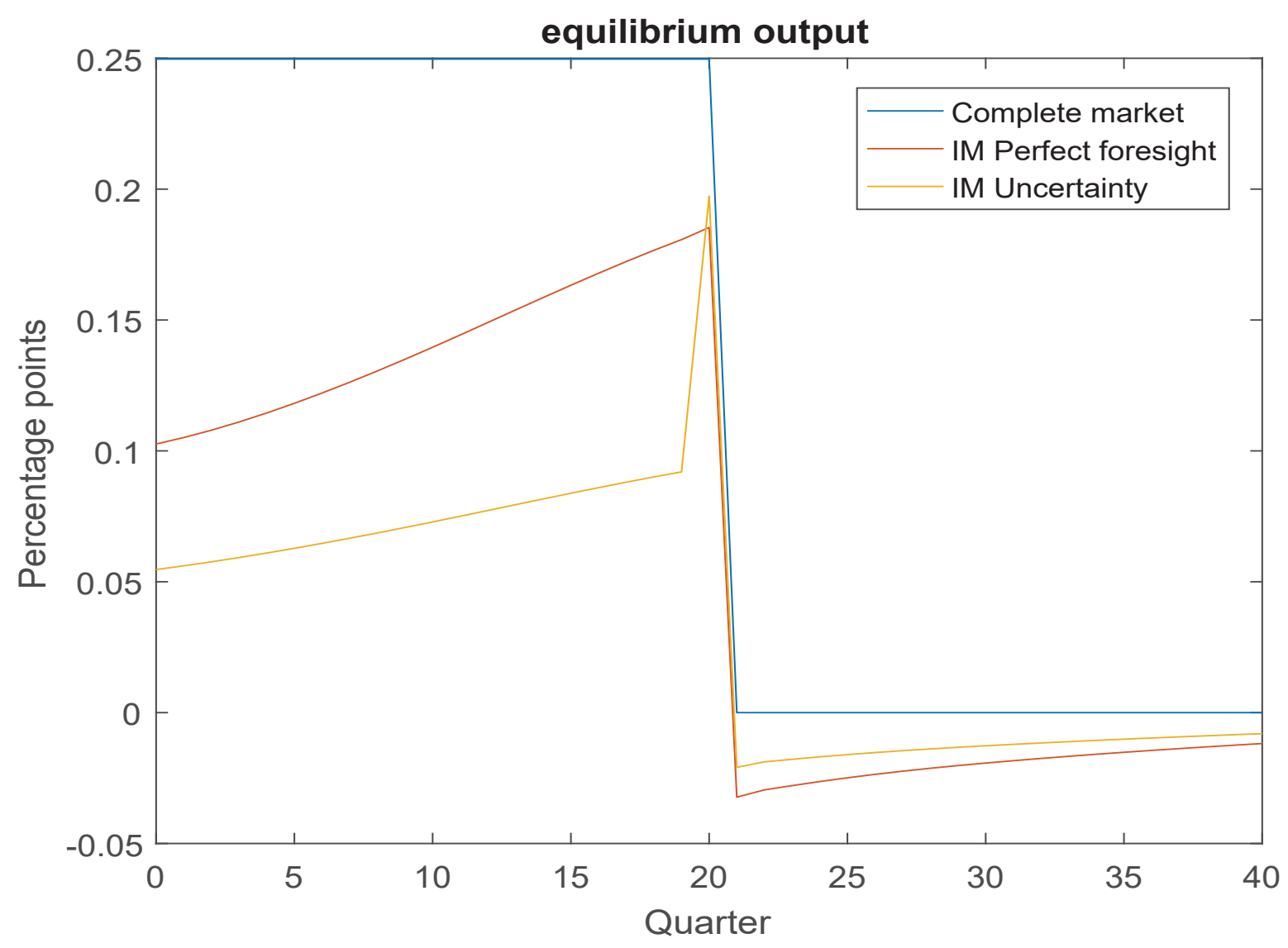




\section{Online Appendix}

\section{A Baseline Index Construction}

The MPU index reflects automated text-search results for the newsstand edition of three major newspapers: New York Times, Wall Street Journal, and Washington Post. We use the ProQuest Newsstand database to search the electronic archives of each newspaper from January 1985 to January 2016 for terms related to monetary policy uncertainty. In particular, the search identifies articles containing the triple of (i) "uncertainty" or "uncertain," (ii) "monetary policy" or "interest rate" or "Federal funds rate" or "Fed fund rate," and (iii) "Federal Reserve" or "Fed" or "Federal Open Market Committee" or "FOMC". Based on these search criteria, we count in each newspaper how many articles contained the search terms above every day.

To deal with changing volume of newspapers over time, we normalize as follows. First, we divide, for each newspaper, in every inter-meeting period, the raw count of articles related to monetary policy uncertainty by the total article count mentioning the Fed. For each newspaper $i$ in period $t$, we calculate the share of articles containing monetary policy uncertainty terms as

$$
n(i, t)=\frac{\# \text { mpu_articles }(i, t)}{\# \text { Fed_articles }(i, t)} .
$$

We then normalize the share of articles so that, for each newspaper, the resulting series has a standard error of one over the sample period. This normalization controls for the possibility that different newspapers mention monetary policy uncertainty with different frequency over time. That is, we denote the normalized share of articles using

$$
n n(i, t)=\frac{n(i, t)}{\operatorname{stdev}(n(i, 1985: 2015))} .
$$

Finally, we sum the $n n(i)$ series across newspapers and scale them so that the average value is 100 over the sample period. The scaling produces our monetary policy uncertainty index, denoted as MPU:

$$
M P U(t)=\left[\frac{\sum_{i} n n(t)}{\operatorname{avg}\left(\sum_{i} n n(1985: 2015)\right)}\right] \times 100 .
$$

A human reading of a sample of the articles suggests that the news-based approach used to construct the index can provide a reasonable indicator of monetary policy uncertainty. Newspapers typically cite uncertainties related to monetary policy in one of the following cases:

- Newspaper articles comment on the uncertainty resulting from Federal Reserve actions. For example, "FOMC reserve injection during the day is reversed at the overnight closing time to achieve an artificial 5.25\%. This target Fed funds chicanery leaves the financial market with considerable uncertainty." 
- Newspaper articles discuss the implications of uncertainty regarding the Federal Reserve actions for the real economy and stock markets. For example, "Traders last week blamed uncertainty about the FOMC for the sharp ups and downs on the New York Stock Exchange."

- Newspaper articles analyze uncertainties at home and abroad that affect monetary policy. For example, "Given the inherent uncertainty about future developments, policy actions often importantly depend on the flow of new information and the FOMC's judgment about its implications." "There are significant uncertainties about the Fed moving to boost the cost of borrowing in the U.S. as China's economy has run into trouble and as financial markets have suffered significant losses."

- Newspaper articles quote policy-makers, economists, political leaders, or industry experts who refer to uncertainties in relation to monetary policy in their speeches or interviews. For example, "The Federal Open Market Committee, the central bank's top policymaking group, blamed the slowdown in growth largely on falling stock prices and 'heightened uncertainty related to problems in corporate reporting and governance'." 


\section{B Additional data checks}

Saiz and Simonsohn (2013) propose a number of data checks to examine whether an index is a useful proxy for the phenomenon of interest. We follow these conditions and check the validity of our index below.

1. Do the different queries maintain the phenomenon and keyword constant?

Following Saiz and Simonsohn (2013), two data checks are used to assess the validity of this premise. First, we verify that our MPU index is expressed in terms of a relative frequency. Second, the keyword chosen be more likely to be employed following the occurrence than the non-occurrence of the phenomenon of interest. We verify this by calculating that $85 \%$ of the randomly selected articles from set $M$ (i.e., those included in our computer-automated index).

2. Is the variable being proxied a frequency?

Our index is a frequency.

3. After sampling the contents of documents found: is the keyword employed predominately to discuss the occurrence rather than non-occurrence of phenomenon?

We verify this in our human auditing: $85 \%$ of the randomly selected articles from set $M$ (i.e., those included in our computer-automated index).

4. Is the average number of documents found large enough for variation in document-frequency to be driven by factors other than sampling error?

We verify this in two ways. First, we gain confidence in our human audit that (i) the average number documents found is sufficiently large for meaning variations and (ii) our index spike up on the days of notable events that are associated with rising monetary policy uncertainty, for example, 2003 Iraq invasion, 2013 Taper Tantrum, and 2015 December liftoff uncertainty, not only on the monthly basis but also on a daily frequency.

5. Is the expected variance in the occurrence-frequency of interest high enough to overcome the noise associated with document-frequency proxying?

Saiz and Simonsohn (2013) argue that one likely source of measurement error is keywords with multiple meanings leading to false positives; that is, to documents that do contain the key words but which are not actually about the phenomenon of interest. This can be easily fixed by replacing a keyword for a synonym with fewer other meanings. Our human audit and, in particular, our analysis of the error rate, show small measurement errors in our index and help alleviate this concern. In fact, our reading of both set $M$ (those articles included in MPU index) and set $E$ (a larger set that contains only words in category (iii)) suggests that our MPU index is rather conservative because of relatively restrictive search criteria. 
6. After inspecting the content of the documents found: does the chosen keyword have as its primary or only meaning the occurrence of the phenomenon of interest?

The final aspect of data checks deals with a possible correlation of the index with covariates of other variables of interest: conditioning on occurrence-frequency, document-frequency should be uncorrelated with the covariates of interest (Saiz and Simonsohn (2013)). We address this by (i) scaling our index by the number of articles mentioning Fed (see more details in data check \#8) and (ii) showing that our index is not correlated with other major economic outcome variables.

7. After inspecting the content of the documents found: does the chosen keyword also result in documents related to the covariates of the occurrence of interest?

See our response for data check \#8.

8. Are there plausible omitted variables that may be correlated both with the documentfrequency and its covariates? If so, control for the omitted variable with an additional placebo document-frequency variable.

We control for the potentially time-varying public attention on Federal Reserve (that may or may not be unrelated to uncertainty) by scaling our index by the total number of articles each month mentioning the Fed. In so doing, we control for the time variation in the volume of newspaper articles as well as that in concerns about the Federal Reserve in general. This is also a key difference between our index and that constructed by Baker, Bloom, and Davis (2016).

\section{The Survey of Primary Dealers index details}

For each dealer $i$ in period $t$, we use $\operatorname{Er}(i, t)$ to denote the expected value of the interest rate at the upcoming meeting, calculated as the policy rate in place prior to the survey $r(t-1)$ plus the expected change in the policy rate computed from the possibilities each dealer $i$ assigned to the pre-specified bins $(b=\{1, \cdots, n\})$ :

$$
\operatorname{Er}(i, t)=r(t-1)+\sum_{b=1}^{n} \operatorname{Pr}(b, i) d(b)
$$

where $d(b)$ denotes the value of a possible rate change specified in each bin, for example, 0 , $+/-25 \mathrm{bps}$, or $+/-50 \mathrm{bps}$; and $\operatorname{Pr}(b, i)$ is the probability dealer $i$ assigned to each bin $b$.

For the policy rate set two meetings ahead, we calculate dealer $i$ 's expected rate as his own expected rate at the upcoming meeting plus the expected change in the policy rate two meetings ahead computed from the bins. That is, we replace the actual policy rate prior to the survey $r(t-1)$ by $\operatorname{Er}(i, t)$ in the expectation calculation. By the same token, we use dealer $i^{\prime} s$ 
own expected policy rate two meetings ahead as the basis to compute his expectation for three meetings ahead.

The degree of uncertainty perceived by dealer $i$ for $m=\{1,2,3\}$ meetings ahead, denoted by $U(i, m)$, is calculated as the standard deviation of his forecasted rate for $m$ meetings ahead. The uncertainty measure in period $t$ for $m$ meetings ahead is then the average of all the uncertainty measures for the dealers $m$ meetings ahead. The disagreement measure for $m$ meetings ahead is the standard deviation of the expected policy rate $m$ meetings ahead among the dealers.

Finally, there is time variation in the survey questions. There are questions about the target interest rate only from February 2005 through September 2012. As the Fed Funds rate reached the ZLB and forward guidance ramped up, uncertainty about the interest rate fell to zero quickly. This question was dropped after September 2012 presumably because it did not provide useful information during the ZLB. In addition, the possible bins given in the survey question evolve with the level of the target policy rate. For example, at the beginning of the sample when a reduction in the target rate was unlikely, the possible bins were restricted to a change of 0 , an increase of 25 basis points, and an increase of 50 basis points. Such time variation in the bins should not affect the consistency of our measure because we assume that survey questions are tailored to real possibilities. That is, the probability associated with, say a decrease of 25 basis points for any respondent in this period would be approximately zero anyway, so the fact that they were not asked this does not change the expected value or dispersion of the perceived target. The survey question appropriately added increasingly drastic negative changes in the target rate during the onset of the financial crisis. Finally, the survey question changed format in 2009. Instead of asking about the likelihood of an increase or decrease of a certain number of basis points from the current target, the survey asked about the likelihood of maintaining a certain target rate $(0-25 \mathrm{bps}, 25 \mathrm{bps}, 50 \mathrm{bps}, 75 \mathrm{bps})$. Using the mean/median of $0-25$ bps as the point forecast for the first bin, it is straightforward to see that the former question and the updated question for the ZLB are mathematically equivalent.

\section{Baker, Bloom, and Davis' (2016) Monetary Policy sub- index of EPU}

We begin by noting the relatively low correlation between MPU-HRS and MPU-BBD, which is .49 over the full sample and (.31) after 2008. Their index has more pronounced spike-ups than ours early in the sample, remained well below average throughout 2014 and into 2015, and is subdued relative to our index during the October 2015, December 2015, and January 2016 FOMC meeting intervals.

To try and understand this, we first examine the role of scaling. The correlation between MPU-HRS and MPU-(HRS terms, HRS papers, BBD scaling) is .85 (.92, post-2008). The correlation between MPU-BBD and MPU-(HRS terms, HRS papers, BBD scaling) is .46 (.46). 
These two cases, against the backdrop of the weak correlation between MPU-HRS and MPUBBD, indicate that scaling does not matter much: in the former, we see that changing MPU-HRS only by adopting the BBD scaling maintains a high correlation with MPU-HRS, while the latter case indicates that this same strategy change leaves the resulting index weakly correlated with MPU-BBD.

Second, we examine the role of the keyword search. The correlation between MPU-HRS and MPU-(BBD terms, HRS papers, HRS scaling) is .75 (.76), while that between MPU-BBD and MPU-(BBD terms, HRS papers, HRS scaling) is .42 (.57). These two cases tell us that changing terms matters a little bit more than scaling. That is, the former says that changing MPU-HRS only by using the BBD keyword search leaves a decently high correlation with MPU-HRS, though not super high, while in the latter case we learn that changing MPU-HRS only to use the BBD keywords leaves the resulting index weakly correlated with MPU-BBD (though notably higher post-2008).

Third, and finally, we examine MPU-HRS vs. MPU-(BBD terms, HRS papers, BBD scaling), and find correlations of .62 (.68), and MPU-BBD vs. MPU-(BBD terms, HRS papers, BBD scaling) with correlations of .39 (.72). These last two cases are more difficult to assess. For the most part they suggest that if all BBD were to do was use only our smaller set of newspapers, there would be a decent correlation with our MPU-HRS index and in the full sample period a poor correlation with what they compute from using the large set of newspapers. This indicates that newspaper choice matters. Baker, Bloom, and Davis (2016) use the Access World News database of over 2,000 newspapers, while we use the three major U.S. newspapers that are more tailored to national financial news.

We conclude from our reconciliation analysis that in order of importance, the factors explaining the weak correlation between MPU-HRS and MPU-BBD can be ranked: (1) Newspapers, (2) Keywords, and (3) Scaling. Given their significantly larger set of search terms and newspapers, it is likely that theirs captures a relatively larger global factor while ours is more U.S. centric.

\section{E Proximate Determinants of MPU}

\section{E.1 Dissenting votes}

The Federal Open Market Committee consists of the seven Federal Reserve governors and five Federal Reserve Bank presidents on a rotating basis. The FOMC ordinarily meets eight times per year and at each meeting votes on a directive that governs monetary policy during the period between meetings. The policy directives are usually supported by a strong majority but voting often involves dissent (Figure E.2). Dissent could reflect fundamental disagreement about how to achieve the Committee's objectives and could potentially represent shocks to the preferences of the monetary authority. The FOMC dissenting votes have been revealed in the postmeeting statements only since March 2002. However, they have been included in the minutes since the 
mid 1990s. Recalling that we lag dissenting votes by one period, it is not ill-designed to examine the relationship with MPU before March 2002.

In the first row of Table 1, we show that there is a positive correlation between the percentage of FOMC dissenting votes at one meeting and the level of MPU during the following inter-meeting period. A "united front" of the FOMC participants does seem to convey to the public that a sudden deviation from the central bank's reaction function due to preferences shocks is unlikely in the near term. The effect is not particularly significant, however.

\section{E.2 Statement persistence}

The Federal Open Market Committee's postmeeting statements constitute one of the key vehicles through which the Committee communicates its assessment of the economy, its policy actions, and its thinking about future policy. In February 1994, Chairman Greenspan issued the first postmeeting statement following the FOMC's decision to tighten monetary policy - the first increase in the target federal funds rate since 1989. For the next five years, a statement was released only after meetings in which the FOMC decided to change rates, but in May 1999 the committee began releasing statements at the conclusion of every meeting.

Using techniques developed in computational linguistics, Meade and Acosta (2015) construct a measure of how persistent the content of the statements has been, by calculating the correlation (similarity) of words used in two consecutive postmeeting statements. If identical words are used in consecutive FOMC statements, ignoring changes in word order, the similarity will equal unity. The addition or subtraction of words or the use of the same words in different proportions will reduce similarity between consecutive meetings.

The Meade-Acosta measure of statement persistence is displayed in Figure E.3, along with MPU. Meeting-to-meeting similarity rose between May 1999 through mid-2007. It then fell to an historic low (below 0.20) between the October 2008 and December 2008 meetings when the FOMC reduced the Fed Funds target rate to a range of 0 to $1 / 4$ percent amid a widening crisis. Average persistence declined during the financial crisis and then rose to a very high level through 2014.

As shown in Table 1, we find a negative correlation between persistence in FOMC statements (from the previous meeting to the current) and monetary policy uncertainty perceived by the public (regarding the period up to the next meeting). When the semantic content of FOMC statements from one meeting to the next is similar, the public seems to perceive little change in the central bank's policy stance and projects limited uncertainty going forward.

\section{E.3 Uncertainty perceived and conveyed by the central bannk}

"Part of the game is confidence, and looking clueless and uncertain doesn't help."

- Ben Bernanke (2015) 
We conjecture that the public's uncertainty regarding monetary policy is influenced by the degree of uncertainty the Federal Reserve itself perceives and conveys. To examine this, we construct indicators of uncertainty conveyed in publicly archived FOMC documents including statements, minutes, testimony, speeches, and the Chair's postmeeting press conferences. We use automated text-search to calculate the frequency of words that suggest uncertainty, including synonyms that are taken from a thesaurus. ${ }^{30}$ Consistent with our conjecture, Table 1 shows that the degree of uncertainty conveyed in FOMC statements and minutes, displayed in Figure E.1, is positively correlated with contemporaneous monetary policy uncertainty that the public perceives, but only weakly so. Uncertainty conveyed in FOMC speeches and testimonies is also only weakly correlated with MPU.

\section{E.4 FOMC member turnover}

A significant turnover of FOMC members may lead to unanticipated changes in the central bank's policy stance and introduce disparate and unknown voices at the Fed, making it difficult to convince the public with a coherent monetary policy message. Our measure of member turnover is the number of FOMC participants leaving or joining the FOMC for the first time at the current meeting. The coefficients on FOMC member turnover in Table 1 are positive as expected and yet only occasionally significant. One main challenge of identifying the effects of personnel turnover is that such changes are typically anticipated ahead of time (e.g., the recently announced resignation of Governor Tarullo will take place a couple of months hence), and it is difficult to pinpoint when turnover becomes public knowledge. Thus, we do not consider the lack of statistical significance here as dismissing the role of FOMC member turnover in affecting monetary policy uncertainty.

\section{E.5 Endogeneity}

Although we are careful about temporal considerations in correlating our measures with MPU in Table 1, and despite the intuitive appeal of the resulting correlations, inference is complicated by concerns of simultaneity and omitted factors. There likely exists hard-to-measure forces, each with varying degrees of quiescence, which simultaneously create, e.g., more monetary policy uncertainty and less agreement among FOMC members about policy prescriptions. We attempt to make progress by controlling for (reasonable proxies of) such hard-to-measure forces. To this end, we employ measures of U.S. macroeconomic uncertainty and financial uncertainty, geopolit-

\footnotetext{
${ }^{30}$ Uncertain, ambiguous, ambivalent, dubious, erratic, hazy, hesitant, insecure, precarious, questionable, risky (this does not include the noun risk), unclear, undecided, undetermined, unpredictable, unreliable, unresolved, unsettled, unsure, and vague (and their derivatives). We sum instances of these words on a document-by-document basis and divide this raw count by the number of total words in the release. In the case of minutes and statements, the resulting observation is just an addition of these two measures on a meeting-date basis. In the case of the speeches and testimony, this is the summed linear combination of all of the speeches and testimony observations in the inter-meeting period.
} 
ical risk, U.S. defense spending shocks, and U.S. natural disasters. The potential importance of macro or financial uncertainty speaks for itself: uncertainty about FOMC policy actions could be high when the basis on which policy is made, the current and expected future state of the U.S. economy, is perceived as highly uncertain. The appealing feature of the latter three controls is that they are arguably orthogonal to the error terms in the MPU regressions that contain only the FOMC institutional/procedural variables. We briefly describe these controls in the following sub-sections.

\section{E.5.1 Macroeconomic uncertainty and financial uncertainty}

Imperfect information about the current and expected future state of the economy is another source of uncertainty regarding central bank policy. There is measurement error in the preliminary data available to the FOMC at the time it makes decisions. The actual position of the economy at any time is only partially known, as key information on spending, production, and prices becomes available only with a lag (and is furthermore continuously revised). Therefore, policy makers must rely on estimates of these economic variables when assessing the appropriate course of policy, aware that they could act on the basis of incomplete or misleading information. Uncertainty about policy actions could be high when the basis on which policy is made is perceived as highly uncertain by the public. This in turn could be correlated with, e.g., FOMCrevealed uncertainty. To control for this, we use the macroeconomic uncertainty measure of Jurado, Ludvigson, and Ng (2015), an econometric estimate of whether the economy has become less or more predictable, and the financial uncertainty measure of Ludvigson, Ma, and $\mathrm{Ng}$ (2016), which is also estimated - from an iterative projection instrumental variables method. ${ }^{31}$

Contemporaneous uncertainty about the financial state of the economy is positively, and often significantly, correlated with MPU. On the other hand, macroeconomic uncertainty contributes to uncertainty the public perceives about monetary policy in a way that is unstable over time. Prior to 2008, the estimated relationship (not displayed) is positive irrespective of other controls in the regression, while in the regressions that go through 2015 the estimate is negative and sometimes significantly so.

\section{E.5.2 Geopolitical risk, U.S. Defense spending shocks, and U.S. natural disasters}

The geopolitical risk index (Caldara and Iacoviello 2017) is calculated using a methodology similar to that used in constructing our MPU index. They search over 11 major U.S. and British newspapers for mentions of the words: geopolitical risk(s), concern(s), tension(s), uncertainty(ies), war risk(s) (or risk(s) of war) and military threat(s), as well as mentions of terrorist threat(s). Our expectation that geopolitical risk will be positively correlated with MPU is confirmed, and

\footnotetext{
${ }^{31}$ We use their 12-month ahead measures as this is a better conceptual match with our MPU than the 1-month or 3-month horizons. Results are quite similar irrespective of which of their horizon-measures we use. We also find robustness to using Scotti's (2013) alternative measure of macroeconomic uncertainty.
} 
indeed we see that it is quite significant statistically as well.

Ramey (2011) constructs a measure of news about future government spending, by reading news sources to gather quantitative information about expectations. Her defense news variable measures the expected discounted value of government spending changes due to foreign political events. The series was constructed by reading periodicals (e.g., Business Week) in order to gauge the public's expectations. According to Ramey, the constructed series should be viewed as an approximation to the changes in expectations at the time. In calculating present discounted values, she used the 3-year Treasury bond rate prevailing at the time. We estimated all of our regressions with Ramey's measure included. These specifications never produced estimates of her variable with a t-statistic greater than 0.50 , and never had any material effect on the other estimated coefficients, so we do not report these results.

As a final control, we construct a measure of fatalities resulting from notable natural disasters that occurred in the United States. These include cyclones (Rita, Katrina), tornadoes, hurricanes, floods, blizzards, snow storms, earthquakes, and heat waves. ${ }^{32}$ We expect this also to be positively correlated with monetary policy uncertainty. In this case too, the estimated coefficients are not significant.

\section{E.5.3 Instrumental variables}

All of the OLS estimates displayed in Table 1 convey a consistent message: there is an important association between FOMC communications and monetary policy uncertainty, even when controlling for reasonable proxies of omitted factors that might account for some of this relationship. Of course, these additional controls are not playing the role of instruments. Hence, we also estimated regressions for MPU using both two-stage least squares (2SLS) and limited-information maximum likelihood (LIML). We tried a variety of instruments, alone and in combination with each other, including first lags of each of the $\mathcal{X}$ variables and each of our control variables $\mathcal{Z}_{t}$ (as well as the first lag of macro uncertainty). We found that these instruments are "weak", however, leaving us without reliable IV estimates. ${ }^{33}$

Angrist and Kreuger (2001) note that finding good instruments is difficult in practice. They do discuss the popularity of using instruments derived from "natural experiments". Analogous randomized experiments are not likely in our application, however. Just as it is not feasible to coerce a randomly chosen group of people, e.g., to quit smoking, randomization in something like the semantic content of FOMC statements is unthinkable.

\footnotetext{
${ }^{32}$ https://en.wikipedia.org/wiki/List_of_natural_disasters_in_the_United_States.

${ }^{33}$ For example, in the 2SLS estimates we typically found F-statistics from first stage regressions in the neighborhood of 1.0 to 3.5 or lower, well below the recommended cutoff of 10 (Stock and Yogo (2005)). The most valid instrument, unsurprisingly, was lagged macro uncertainty instrumenting for itself.
} 


\section{E.6 Proximate determinants: plots of the series}

The following three figures depict some of the variables described above, namely: "FOMCrevealed uncertainty" (against MPU), (ii) dissenting votes, and (iii) FOMC statement persistence (against MPU).

Figure E.1: MPU and FOMC-Revealed Uncertainty

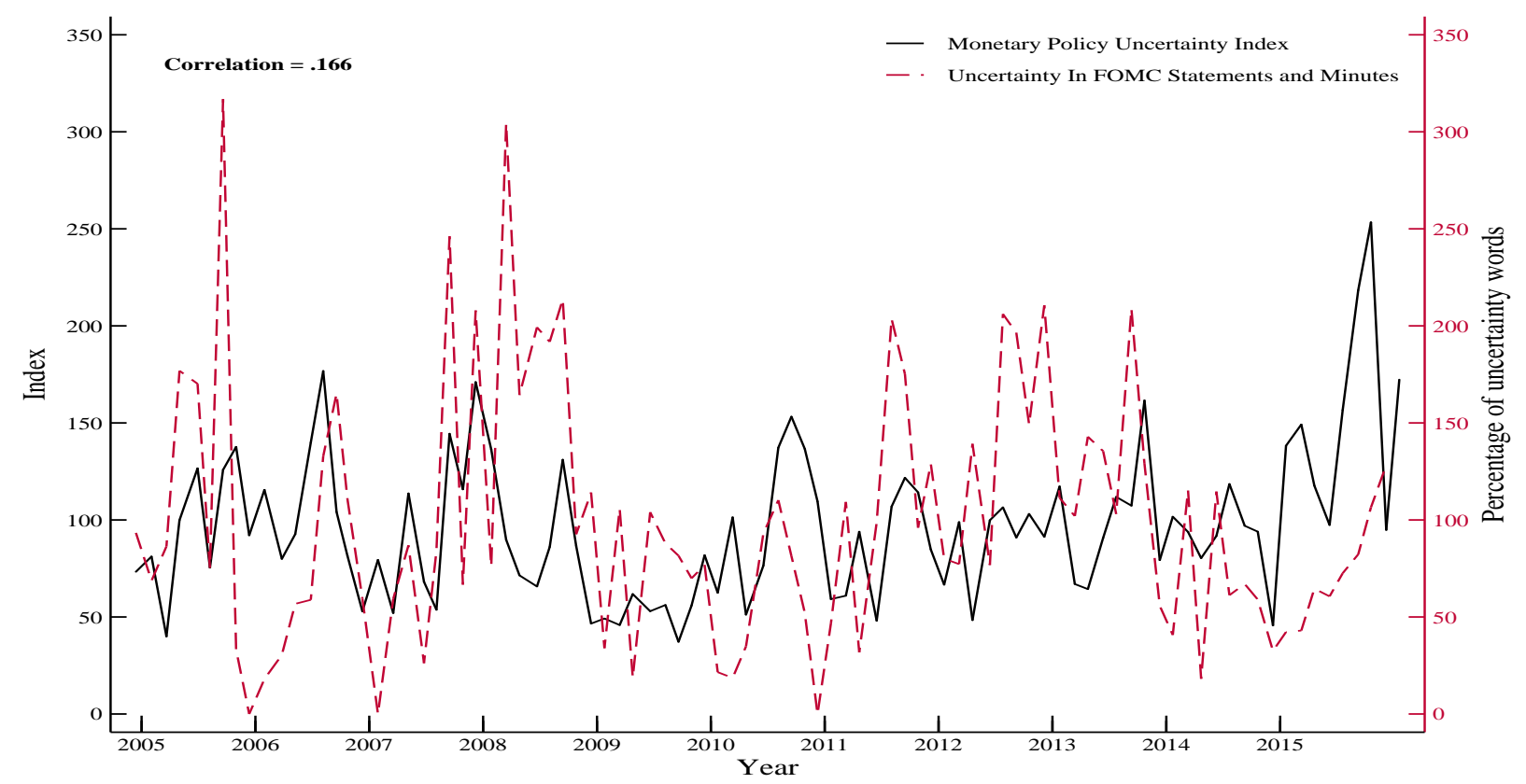

Baseline MPU index against the our measure of uncertainty revealed in FOMC Statements and Minutes. 
Figure E.2: Dissenting Votes

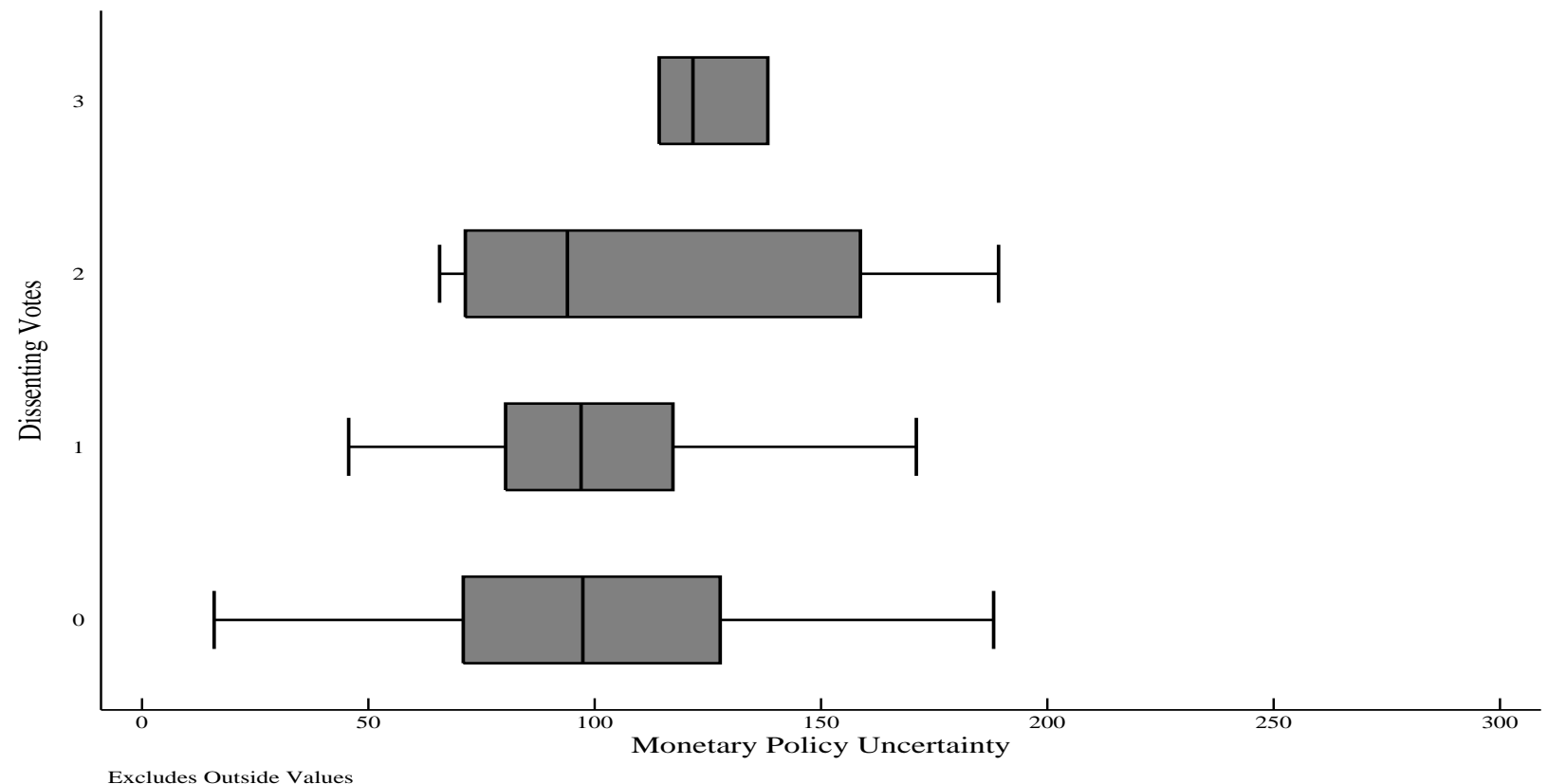

Baseline MPU index against the percentage of FOMC members voting against the Committee decision.

Figure E.3: MPU and Statement Persistence

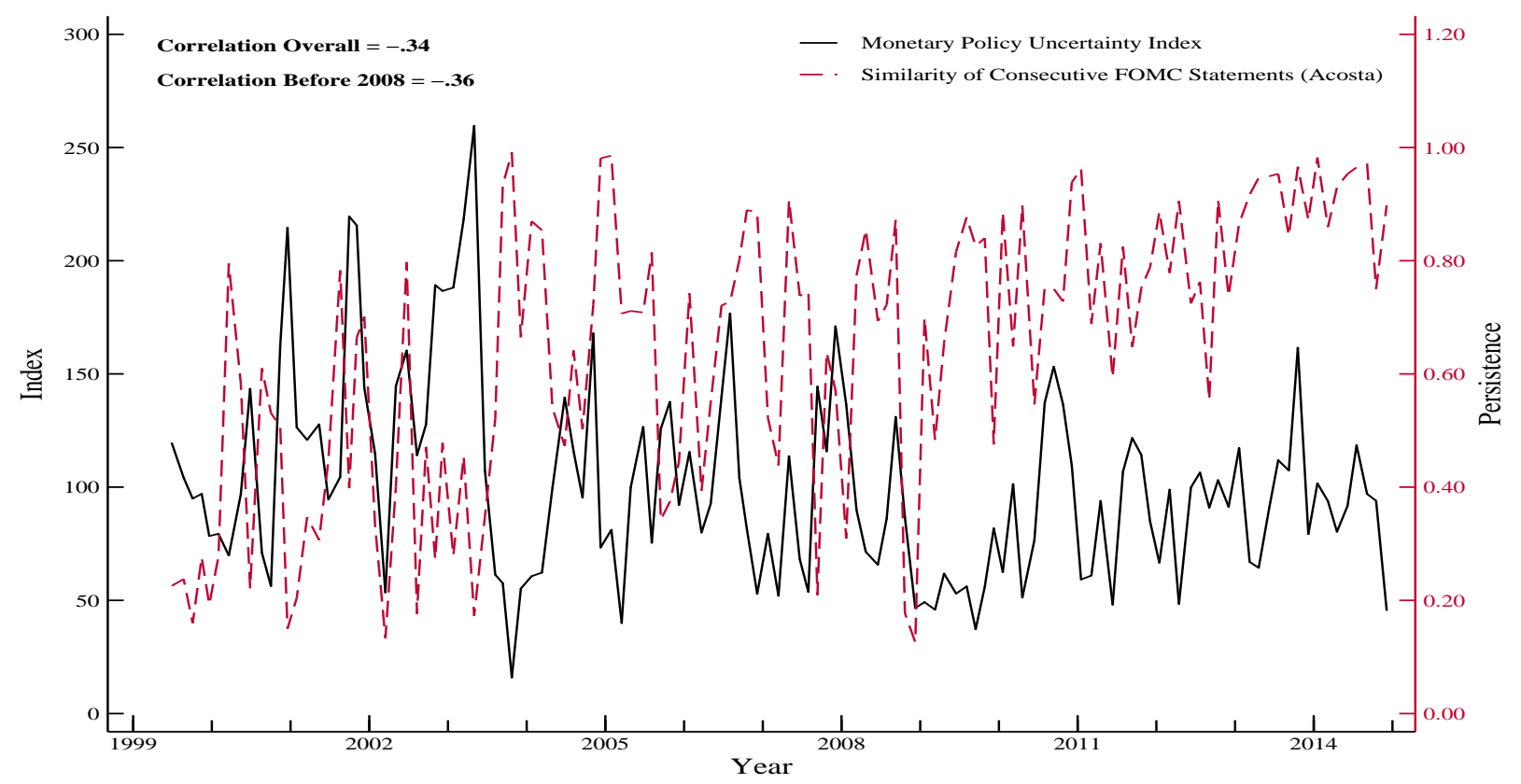

Baseline MPU index against similarity of FOMC statements from meeting to meeting (Meade and Acosta (2015)). 


\section{F VAR Robustness: alternative measures of monetary policy uncertainty}

Figure F.1: Monetary Policy Shock, GK External Instruments Identification, MPU-BBD
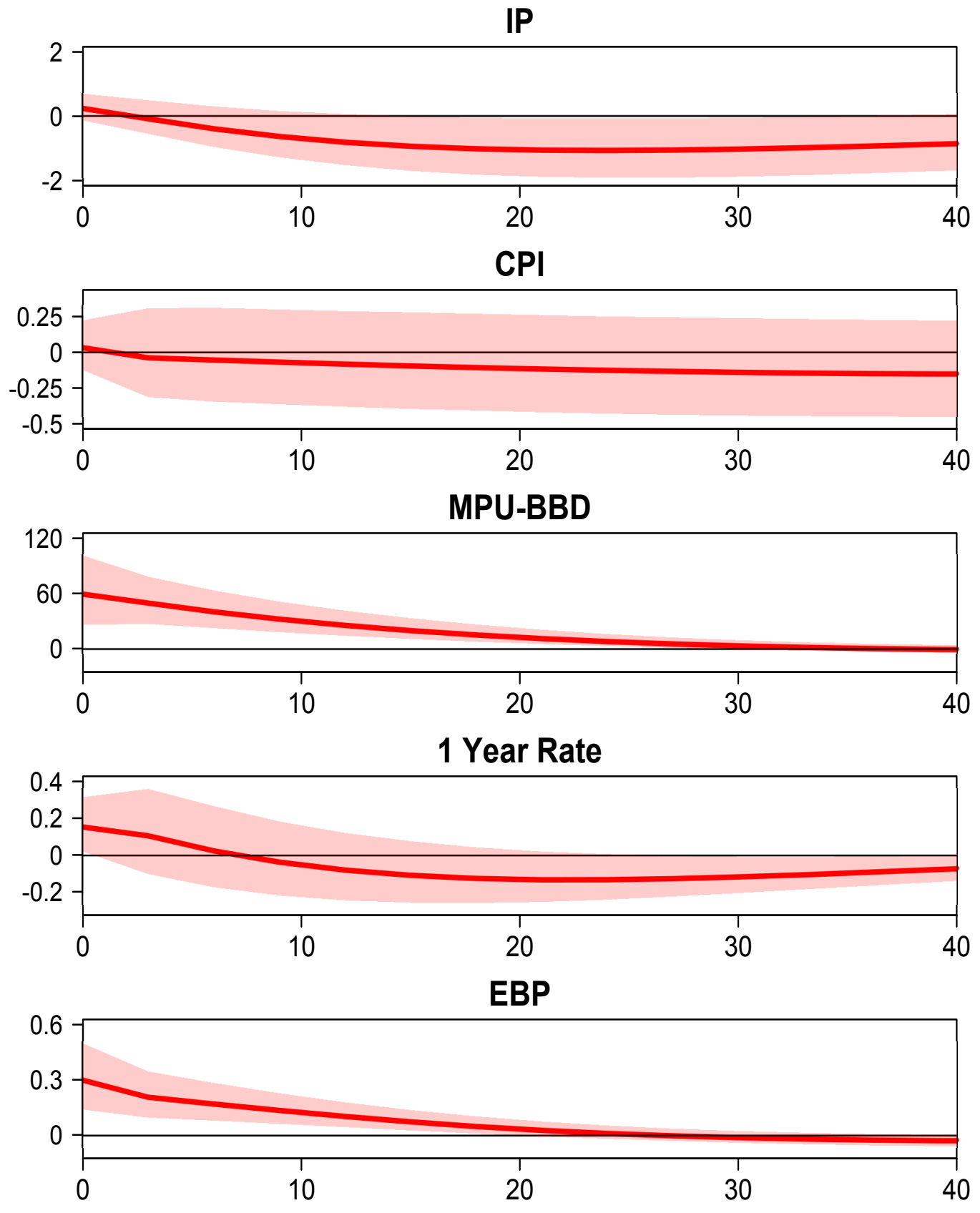

See notes to Figure 5. 
Figure F.2: MPU Shock, Cholesky and Sign Restrictions, MPU-BBD
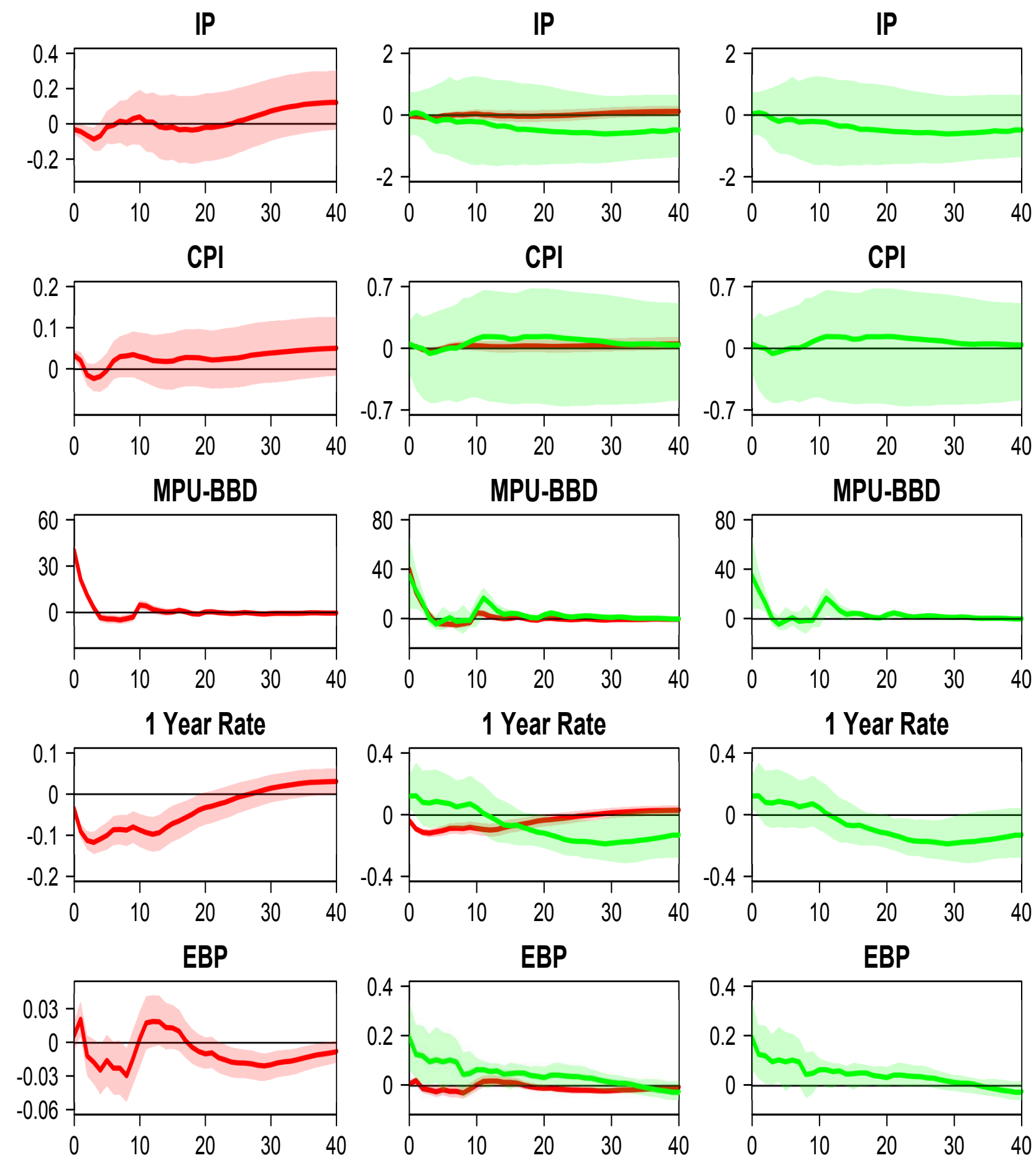

- Cholesky

$\square$ Sign Restrictions

See notes to Figure 6. 
Figure F.3: MPU Shock, External Instruments, MPU-BBD
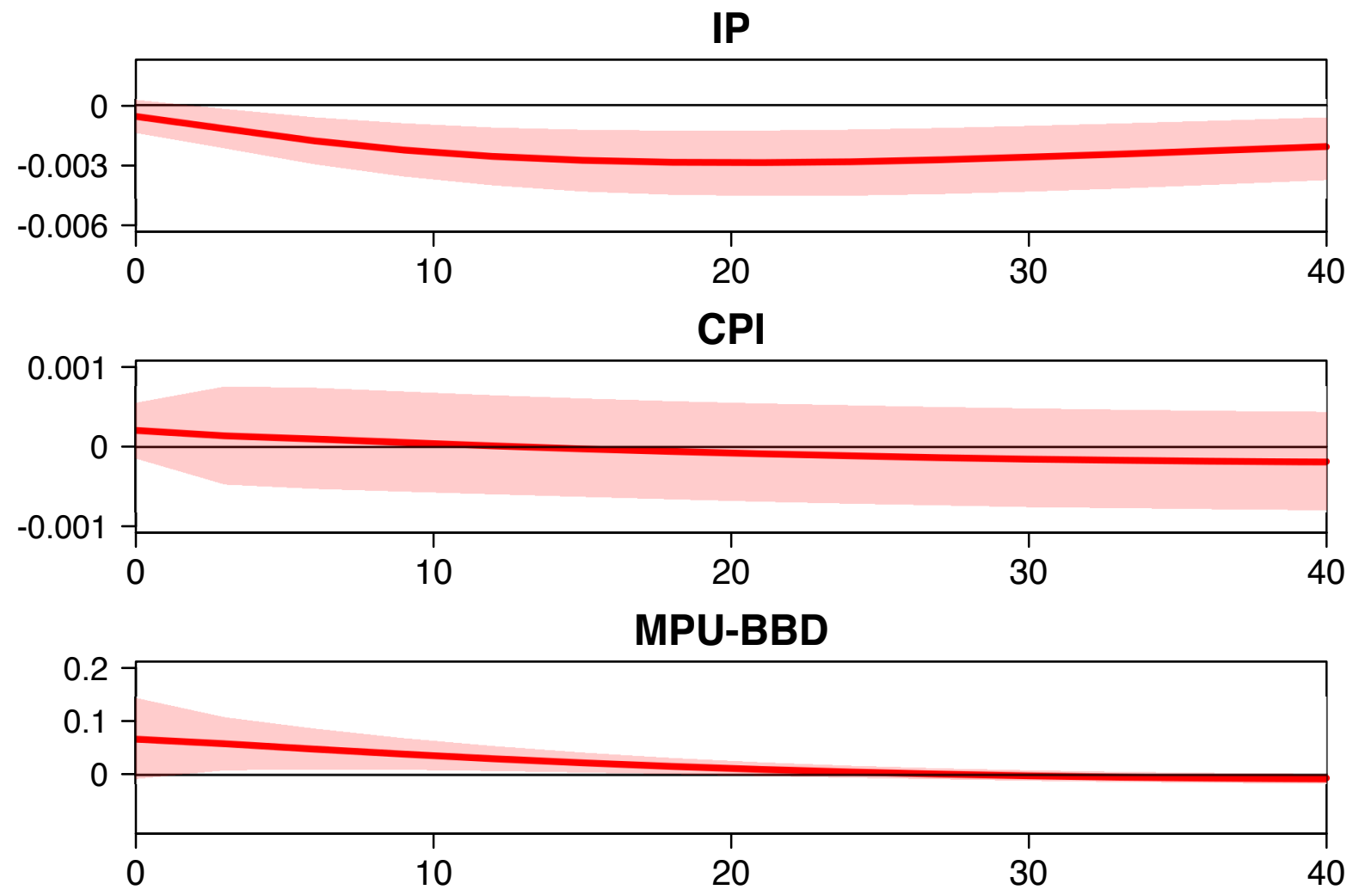

1 Year Rate
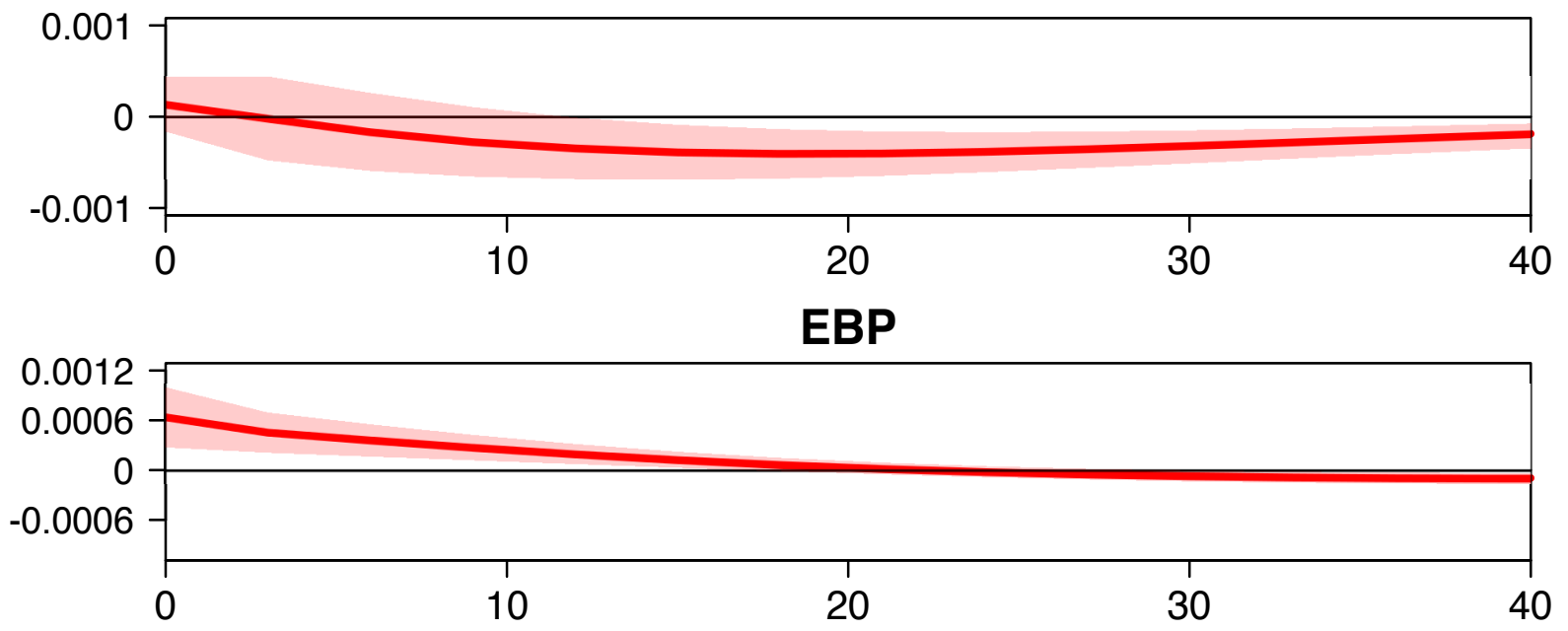

See notes to Figure 7 . 
Figure F.4: Monetary Policy Shock, GK External Instruments Identification, market-based MPU
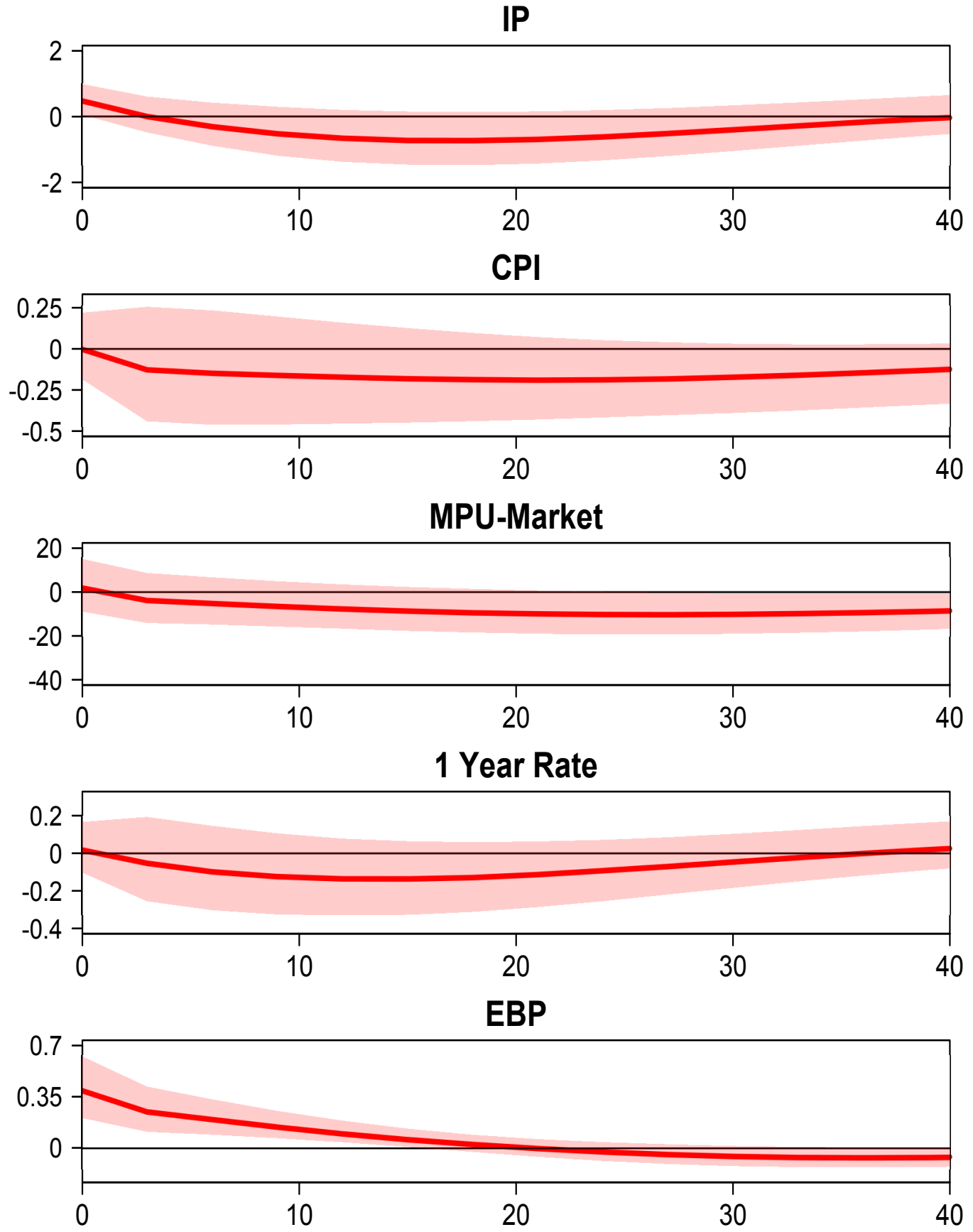

See notes to Figure 5. 
Figure F.5: MPU Shock, Cholesky and Sign Restrictions, MPU-BBD
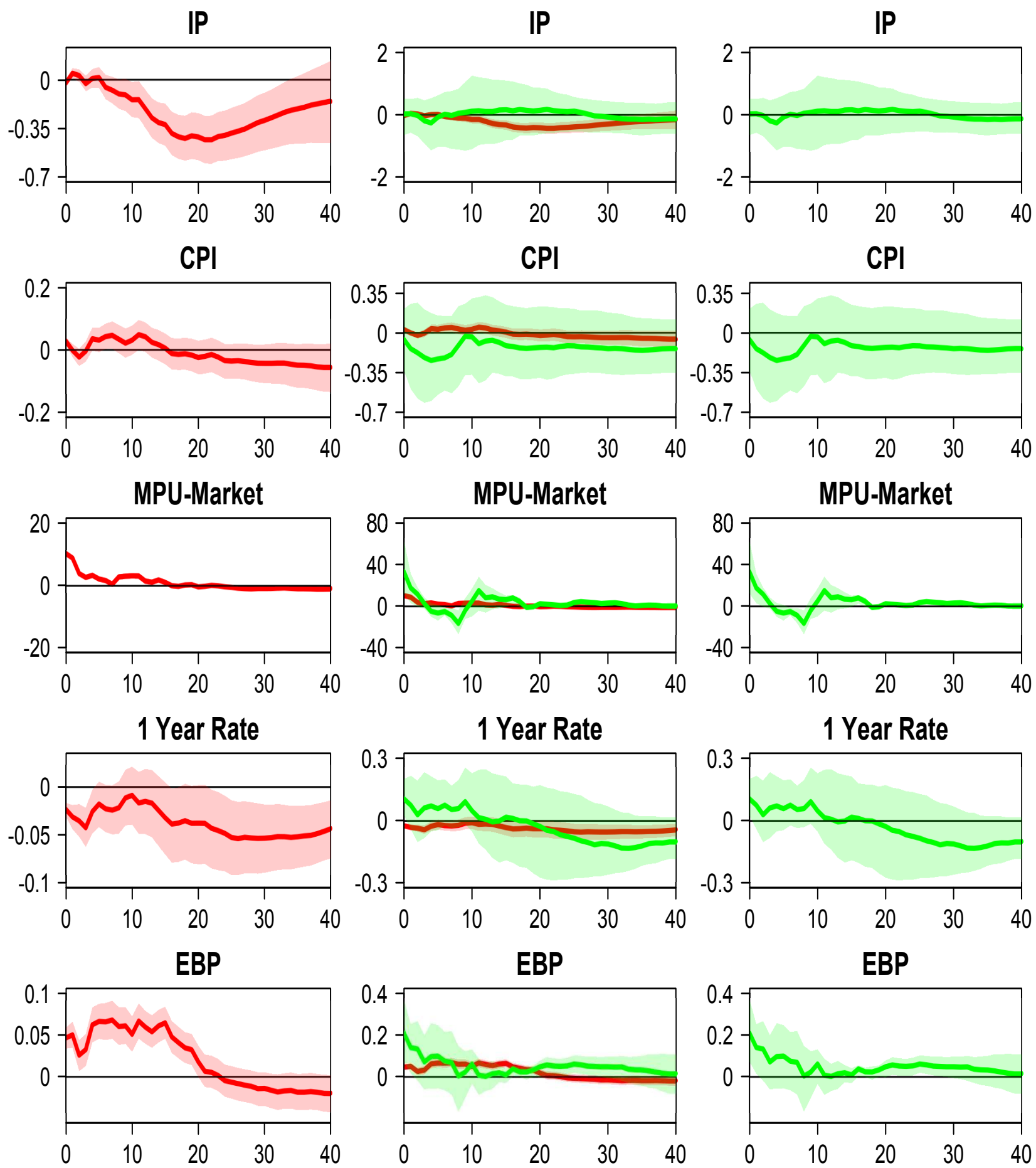

- Cholesky

$\square$ Sign Restrictions

See notes to Figure 6. 
Figure F.6: MPU Shock, External Instruments, market-based MPU
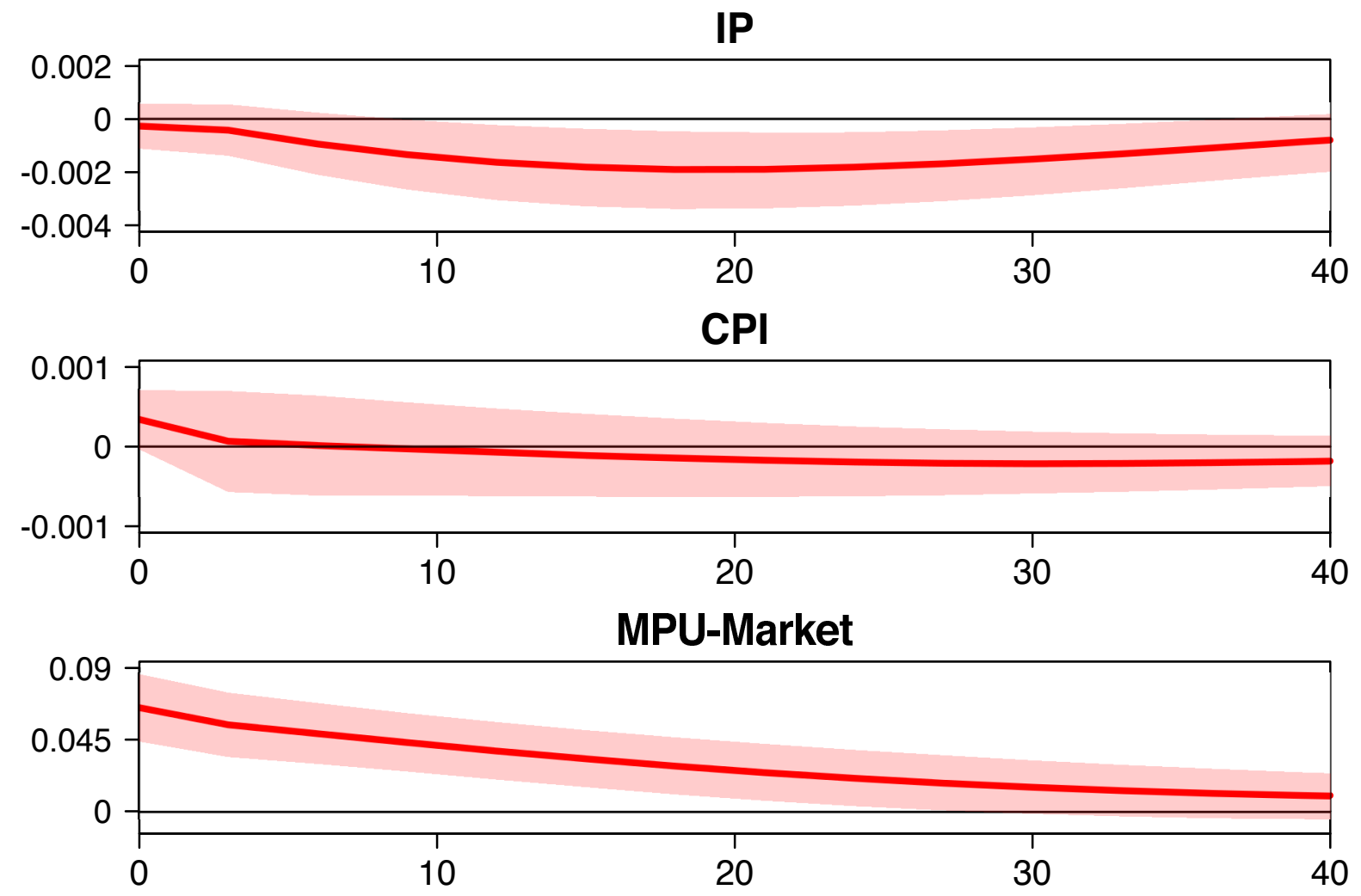

1 Year Rate
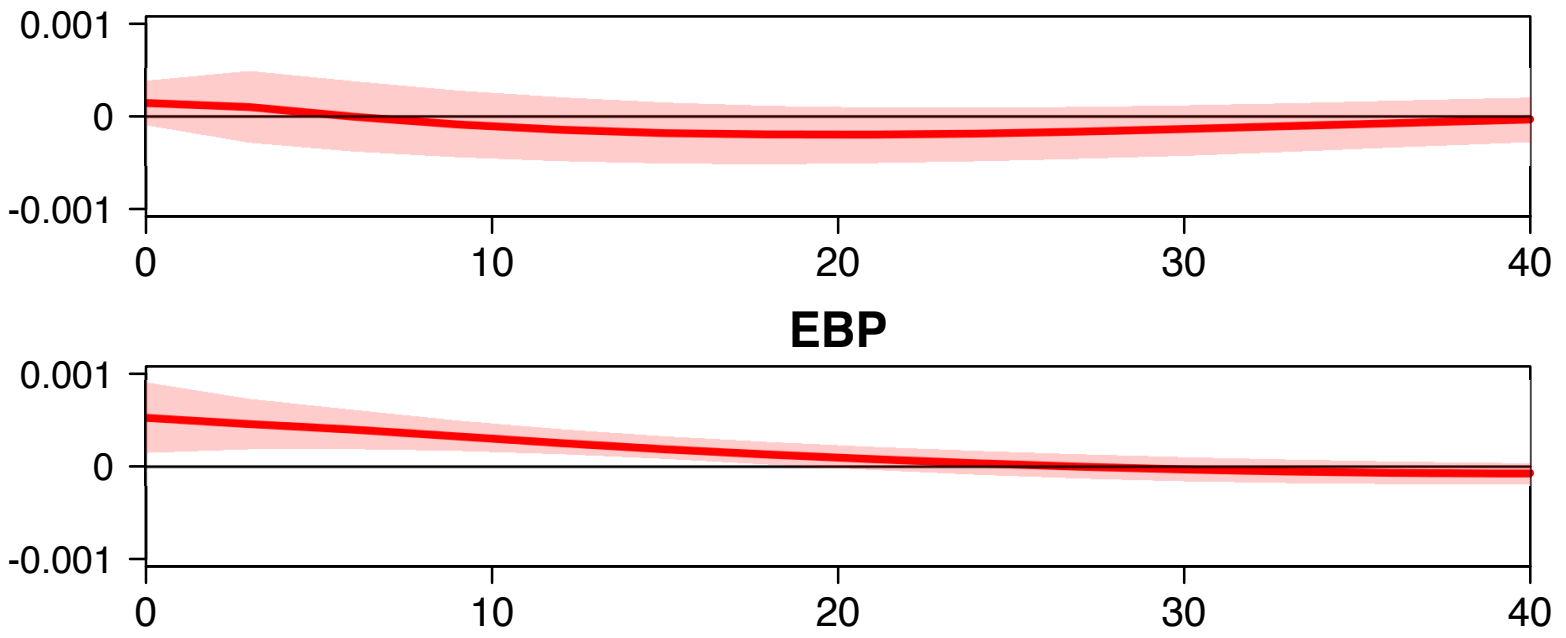

See notes to Figure 7 . 
Figure F.7: MPU Shock, External Instruments, Baseline MPU 1994-2015
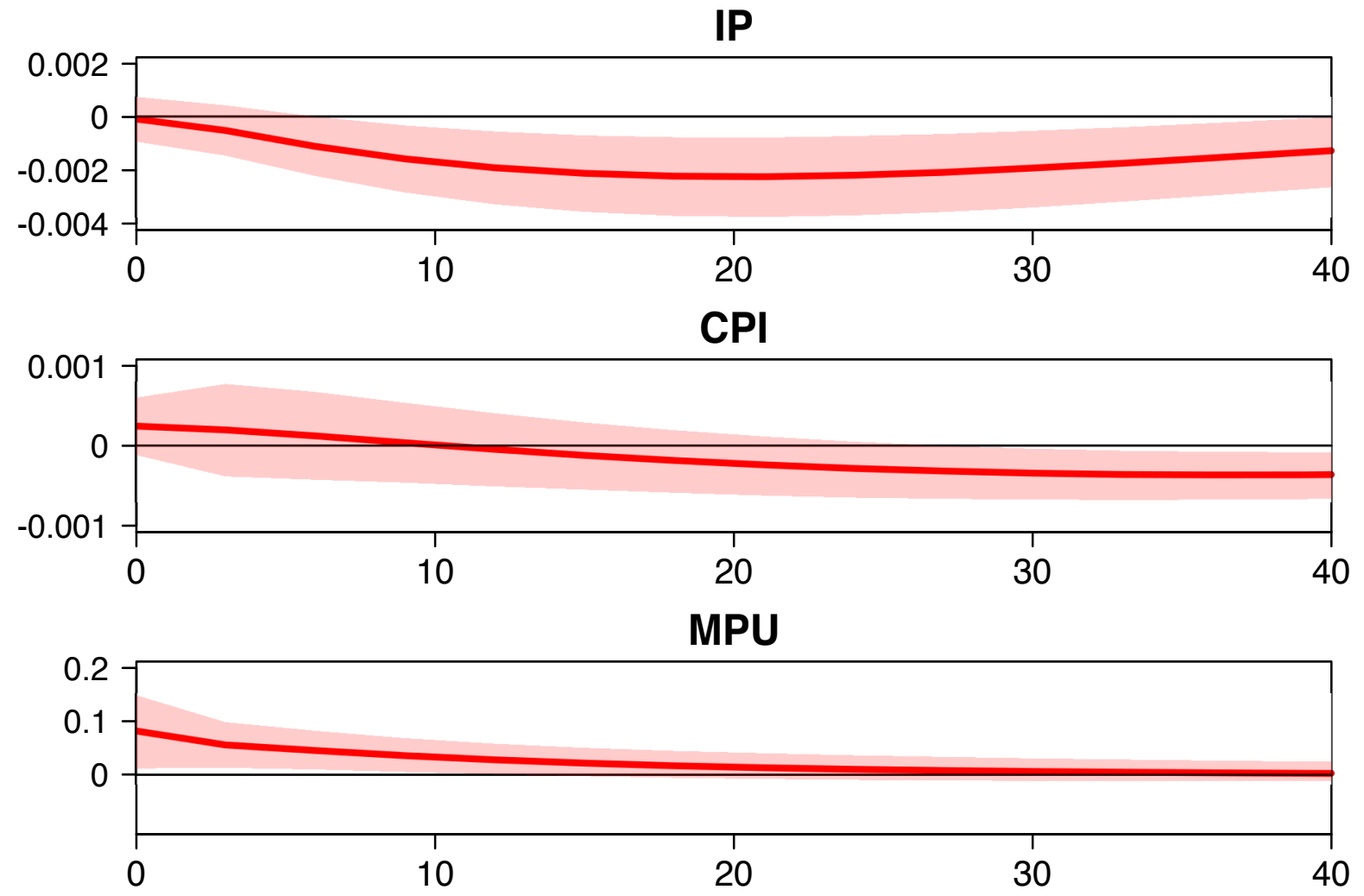

1 Year Rate
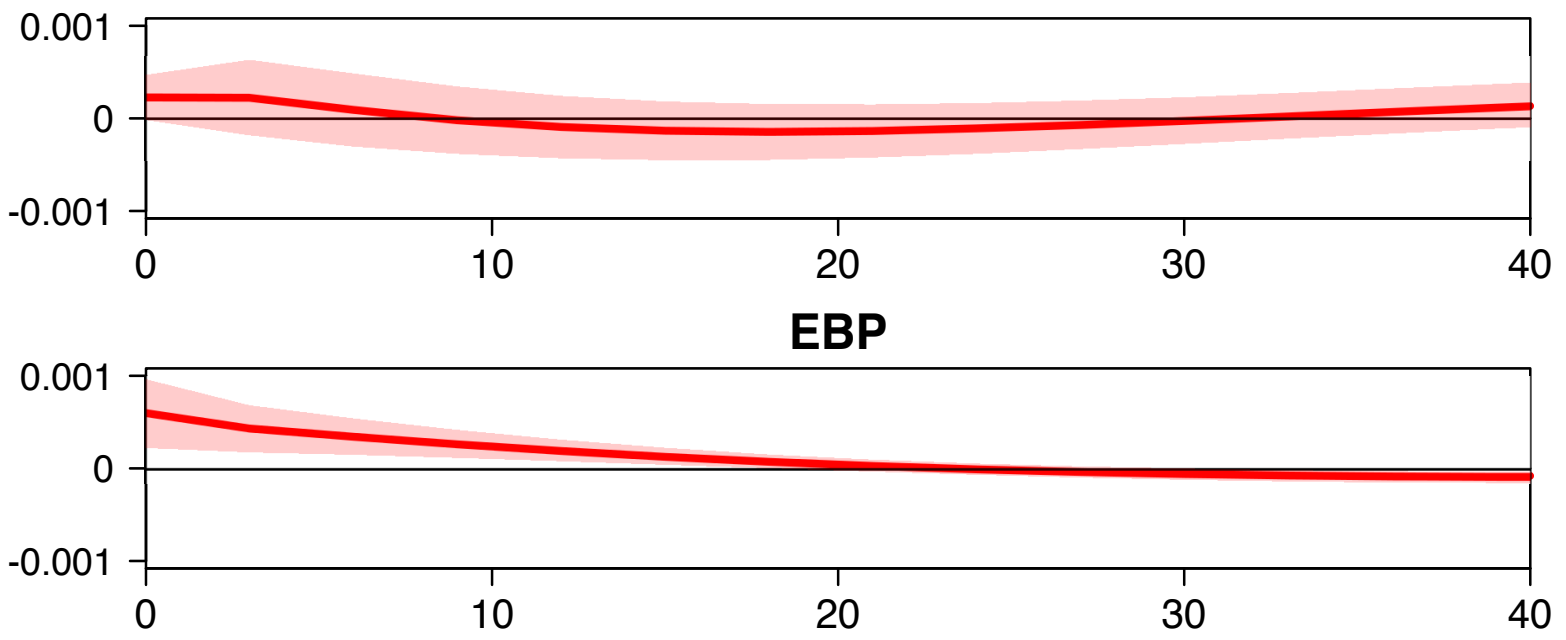

See notes to Figure 7. 